\title{
Effect of Temperature on the Dielectric and Magnetic Properties of NiFe204@MgFe2O4 and ZnFe204@MgFe204 Core-shell
}

Kheled Roumaih ( $\boldsymbol{\nabla}$ khroumaih@yahoo.com )

Egyptian Atomic Energy Authority, Nuclear Research Center, Reactor Physics Department

\section{Research Article}

Keywords: NiFe2O4@MgFe2O4,ZnFe2O4@MgFe204, Core-Shell, dielectric properties, magnetic susceptibility

Posted Date: January 29th, 2021

DOI: https://doi.org/10.21203/rs.3.rs-154061/v1

License: (c) (1) This work is licensed under a Creative Commons Attribution 4.0 International License.

Read Full License 


\title{
Effect of temperature on the Dielectric and Magnetic Properties of $\mathrm{NiFe}_{2} \mathrm{O}_{4} @ \mathrm{MgFe}_{2} \mathrm{O}_{4}$ and $\mathrm{ZnFe}_{2} \mathrm{O}_{4} @ \mathrm{MgFe}_{2} \mathrm{O}_{4}$ Core-Shell
}

Kh. Roumaih

Egyptian Atomic Energy Authority, Nuclear Research Center, Reactor Physics Department.

\begin{abstract}
The core-shell of nanoferrites showed quite different properties rather than the nanoferrites counterpart. The nanocomposites of $\mathrm{NiFe}_{2} \mathrm{O}_{4} @ \mathrm{MgFe}_{2} \mathrm{O}_{4} \quad(\mathrm{NiF} @ \mathrm{MgF})$ and $\mathrm{ZnFe}_{2} \mathrm{O}_{4} @ \mathrm{MgFe}_{2} \mathrm{O}_{4}(\mathrm{ZnF} @ \mathrm{MgF})$ are chemically stable and showed very good dielectric and magnetic properties. In this investigation, the temperature-dependent dielectric constant, dielectric loss, and ac-electrical conductivity were measured up to $650 \mathrm{~K}$ under different alternating electric field frequencies from $100 \mathrm{~Hz}$ to $8 \mathrm{MHz}$. The obtained data revealed that the mutual effect between the core and the shell samples increases the space charge polarization. Also, the samples showed the semiconducting-metallic behavior which varies between SP, CBH, and QMT models according to the temperatures and the frequencies. Furthermore, the magnetization $\mathrm{M}(\mathrm{T})$ was studied of all samples using the Faraday balance method in the temperature range $300-500 \mathrm{~K}$. The experimental results of $\mathrm{M}(\mathrm{T})$ exhibit good magnetic properties of the core-shell samples, particularly the sample $\mathrm{ZnF} @ \mathrm{MgF}$. The novelty in this work is an unexpected behavior of $\mathrm{ZnF} @ \mathrm{MgF}$ which possesses magnetization higher than the pure ferrite phase $\left(\mathrm{MgFe}_{2} \mathrm{O}_{4}\right)$, and Curie temperature $\left(\boldsymbol{T}_{\boldsymbol{C} \boldsymbol{m}}\right)$ higher than the room temperature. So, the sample $\mathrm{ZnF} @ \mathrm{MgF}$ is a ferrimagnetic substance. Besides, the effective magnetic moment ( $\left.\mu_{\mathrm{Eff}}\right)$ and the Curie-Weiss constant $(\theta)$ for all samples were obtained from the magnetic susceptibility $\chi(\mathrm{T})$ protocols.
\end{abstract}

Keywords: $\quad \mathrm{NiFe}_{2} \mathrm{O}_{4} @ \mathrm{MgFe}_{2} \mathrm{O}_{4}, \quad \mathrm{ZnFe}_{2} \mathrm{O}_{4} @ \mathrm{MgFe}_{2} \mathrm{O}_{4}, \quad$ Core-Shell, dielectric properties, magnetic susceptibility,

\section{Introduction}

In the past few decades, the nanocomposites materials made by combining between two different structures such as ferroelectric and ferromagnetic substances, have drawn much attention because of their scientific and technological interest. The nanocomposites have been rapidly developed for their excellent nanoparticles effect above room temperature, which ensures large potential applications in multifunctional devices, transducer, actuators, and sensors. Several 
types of nanocomposites materials in different stacking geometries such as particulate, columnar structures, multilayers, and core-shell nanostructures have been reported [1-4]. The nanocomposites materials made by combining between two nanoferrites substances are rarely studied in the literature although it one of the configurations for multisystem, which allow selection of the useful physical properties by controlling their chemical composition, and the size of the structure.

Ferrites are the magnetic materials exhibiting the cubic spinel structure $[5,6]$. Among the ferrite materials, the $\mathrm{NiFe}_{2} \mathrm{O}_{4}, \mathrm{MgFe}_{2} \mathrm{O}_{4}, \mathrm{ZnFe}_{2} \mathrm{O}_{4}, \mathrm{CuFe}_{2} \mathrm{O}_{4}, \mathrm{MnFe}_{2} \mathrm{O}_{4}, \mathrm{CoFe}_{2} \mathrm{O}_{4}$, etc., are the familiar magnetic spinel structures. Especially, nickel ferrite is a soft magnetic material performing significant magnetic properties [7-17]. In the same way, the different electrical and magnetic properties were also studied to a larger extent in the case of weak magnetic spinel materials such as $\mathrm{MgFe}_{2} \mathrm{O}_{4}$ and $\mathrm{ZnFe}_{2} \mathrm{O}_{4}$ [15-21]. Besides, it was seen in the literature that the non-magnetic elements (like $\mathrm{Mg} \& \mathrm{Zn}$ ) were doped to the pure magnetic spinel system of $\mathrm{NiFe}_{2} \mathrm{O}_{4}$ [22-25]. As a result, the obtained results of $\mathrm{Ni}-\mathrm{Mg}$ and $\mathrm{Ni}-\mathrm{Zn}$ ferrites indicated the variation of the electrical and magnetic properties [22-25]. Moreover, it was evidenced by these reports that the obtained electrical and magnetic properties were dependent on the synthesis technique as well as particle size [23].

The microstructure, morphological, and magnetic hysteresis loops of $\mathrm{NiFe}_{2} \mathrm{O}_{4} @ \mathrm{MgFe}_{2} \mathrm{O}_{4}$, and $\mathrm{ZnFe}_{2} \mathrm{O}_{4} @ \mathrm{MgFe}_{2} \mathrm{O}_{4}$ core-shell nanoparticles have been reported in previous work [4]. In this work, we discuss in detail the effect of temperature on the dielectric properties, and the magnetization of the core-shell $\mathrm{NiFe}_{2} \mathrm{O}_{4} @ \mathrm{MgFe}_{2} \mathrm{O}_{4}$, and $\mathrm{ZnFe}_{2} \mathrm{O}_{4} @ \mathrm{MgFe}_{2} \mathrm{O}_{4}$ nanoparticles.

\section{Experimental and Calculations}

The dielectric measurements were carried out in the frequency range of $100 \mathrm{~Hz}-8 \mathrm{MHz}$ and over a temperature range of 300-650K using the HIOKI IM3536 LCR meter. The pellet contact surface was coated with a high-quality silver paste to make it a disc-shaped parallel plate capacitor with the material as a dielectric medium. The sample holder was mounted in an electric oven for better temperature control. The LCR meter used in the present investigation directly provides the values of capacitance $\mathrm{C}$, Impedance $\mathrm{Z}$, Impedance phase angle $\theta$, and loss factor $\tan \delta$. Other parameters such as dielectric constant $(\varepsilon)$ and ac conductivity $(\sigma)$ are computed using the relations: 


$$
\varepsilon=(\mathrm{C} \times \mathrm{t}) /(\mathrm{A})
$$

and

$$
\sigma=\mathrm{t} /(\mathrm{Z} \times \mathrm{A})
$$

where $C$ is capacitance (in Farad), $t$ is thickness $(\mathrm{cm}), A$ is area $\left(\mathrm{cm}^{2}\right)$.

A Faraday balance is a device for measuring magnetic susceptibility. In this technique, the sample is suspended on a pendulum between electromagnet cores where a magnetic field is applied. The sample is then heated gradually using a non-inductive furnace. After measuring the pull of the balance $(\Delta \mathbf{m})$, many parameters can be calculated such as the molar magnetic susceptibility $\left(\chi_{\mathbf{m}}\right)$, and the molar magnetization $\left(\mathbf{M}_{\mathbf{m}}\right)$ can be calculated using the following relations respectively:

$$
\begin{aligned}
& \chi_{m}=\left[\left(\Delta \mathrm{m} \times \mathrm{g} \times \mathrm{Mw}_{\mathrm{w}}\right)\right] /[\mathrm{m} \times \mathbf{H} \times(\mathrm{dH} / \mathrm{dZ})] \\
& \mathbf{M}_{\mathrm{m}}=\chi_{\mathrm{m}} \times \mathbf{H}
\end{aligned}
$$

where: $\mathbf{g}$ is the gravity $=980.6 \mathrm{~cm} / \mathrm{s}^{2}, \mathbf{M}_{\mathbf{w}}$ is the molecular weight of the sample, $\boldsymbol{m}$ is the mass of the sample, $\mathbf{H}$ is the magnetizing field applied, $\mathbf{d H / d Z}$ is the magnetic field gradient in the $\mathbf{Z}-$ direction.

For simplicity, we will name the pure sample $\mathrm{MgFe}_{2} \mathrm{O}_{4}$ and both core-shell samples $\mathrm{NiFe}_{2} \mathrm{O}_{4} @ \mathrm{MgFe}_{2} \mathrm{O}_{4}$, and $\mathrm{ZnFe}_{2} \mathrm{O}_{4} @ \mathrm{MgFe}_{2} \mathrm{O}_{4}$ by the name $\mathrm{MgF}, \mathrm{NiF} @ \mathrm{MgF}$, and $\mathrm{ZnF} @ \mathrm{MgF}$ respectively.

\section{Results and discussion}

\subsection{Dielectric properties}

Figure 1 shows the variation of the dielectric constant $(\varepsilon)$ of the pure sample $\mathrm{MgF}$, and the both core-shell $\mathrm{ZnF} @ \mathrm{MgF}, \mathrm{NiF} @ \mathrm{MgF}$ in the frequency range $(100 \mathrm{~Hz}-8 \mathrm{MHz})$ and the temperature range (300-650K). From Fig. 1 it is observed that the values of dielectric constant ( $\varepsilon$ ) are high at a frequency range $100-10^{5} \mathrm{~Hz}$ and decrease with an increase in the frequency for

all samples. Thus, these samples show dispersion in the frequency range of $100-10^{5} \mathrm{~Hz}$ which can be explained based on Maxwell-Wagner relaxation behavior as it is dominant in these systems $[26,27]$ and well agreement with Koop's phenomenological theory [28]. At lower frequencies, the higher value of dielectric polarization is due to the contributions from all types of polarizations like dipolar, interfacial, ionic, and electronic. But as the frequency increases the dipoles are unable to follow the applied electric field and the contribution due to dipolar 
interfacial polarization reduces to zero. Hence only electronic polarization contributes to the dielectric constant at a higher frequency; therefore, a lower value of the dielectric constant is obtained. Besides, the NiF@MgF possesses the highest value of dielectric constant than the value of $\mathrm{ZnF} @ \mathrm{MgF}$ as compared to the corresponding $\mathrm{MgF}$. The dielectric properties are mainly affected by microstructure and phase composition [29]. From the previous work [4] the grain size of the $\mathrm{MgF}, \mathrm{ZnF} @ \mathrm{MgF}, \mathrm{NiF} @ \mathrm{MgF}$ nanocomposites is 21, 36, and $159 \mathrm{~nm}$ respectively. Therefore, larger grains possess a higher value of dielectric constant. An increase in grain size may be the reason for a significant increase in the dielectric constant of all samples. Besides that, Reddy et al. [30] explained the increase in dielectric constant in terms of the formation of an extra phase around grain boundaries. The same reason may be responsible for a significant increase in dielectric constant in the present case. The formation of core-shell, which is formed in the present case, is gathered around the grain boundaries causing their overall resistance to increase. The difference in conductivity experienced by charge carriers in the grain interior and grain boundaries may produce an interfacial polarization causing the overall dielectric constant to increase. In the present investigation, although get a low dielectric constant value of the coreshell NiF@MgF and ZnF@MgF, they possess a higher value of dielectric constant as compared to $\mathrm{MgF}$. In other words, this rise in dielectric constant is attributed to the presence of heterogeneity in the composites which agrees with the literature [30-32]. These heterogeneities are the interfaces between the two phases $(\mathrm{MgF} / \mathrm{ZnF}$ and $\mathrm{MgF} / \mathrm{NiF})$ which give rise to space charge polarization and contribute to the dielectric constant. As the electric field is applied the space charge created due to the $\mathrm{NiF}$ phase accumulates at the core-shell interface of the $\mathrm{NiF} @ \mathrm{MgF}$. Therefore with the shell $\mathrm{NiF}$, the space charges created due to $\mathrm{NiF}$ increases subsequently giving higher values for the dielectric constant. Similar behavior has also been reported in different composites such as the core-shell $\mathrm{CuO} / \mathrm{CuFe}_{2} \mathrm{O}_{4}$ [33], the nanocrystalline $\mathrm{CoGd}_{\mathrm{x}} \mathrm{Fe}_{2-\mathrm{x}} \mathrm{O}_{4}$ [34], and the multiferroic composites $\mathrm{BaTiO}_{3}-\mathrm{NiFe}_{2} \mathrm{O}_{4}$ [35].

In spinel ferrites, electric polarization is determined by electron exchange between $\mathrm{Fe}^{2+}$ and $\mathrm{Fe}^{3+}$ ions in octahedral sites resulting in the local displacement of electrons in the direction of the electric field. Variation in $\mathrm{Fe}^{2+}$ concentration affects dielectric variation; hence polarization and dielectric constant are expected to increase with $\mathrm{Fe}^{2+}$ concentration in octahedral sites. In our case, the heterogeneity composites were made by two nanoferrite substances. So, the core-shell of two nanoferrites materials can improve the properties of the heterogeneity 
composites resulting. The probable mechanism for the electron and hole exchange in the ferrite phase can be represented as:

$$
\begin{aligned}
\mathrm{Fe}^{2+} \leftrightarrow \mathrm{Fe}^{3+}+\mathrm{e}^{-} \\
\text {T.E. }^{2+} \leftrightarrow \text { T.E. }^{3+}+\mathrm{e}^{-} \\
\text {T.E. }^{2+} \leftrightarrow \text { T.E. }^{+}+\mathrm{e}^{+} \text {(hole) }
\end{aligned}
$$

where T.E. is the divalent transition element.

The temperature dependence of the dielectric constant $(\varepsilon)$ of $\mathrm{MgF}, \mathrm{NiF} @ \mathrm{MgF}$, and $\mathrm{ZnF} @ \mathrm{MgF}$ nanoparticles at different frequencies is shown in Fig. 2. It is observed from Fig. 2 that the $\varepsilon-\mathrm{T}(\mathrm{K})$ curve has a broadened peak in the low-temperature region due to all types of polarizations like dipolar, interfacial, ionic, and electronic. In other words, at low temperature, the mobility of charge carriers increases with increasing temperature, which leads to an increase in the conductivity and polarization of the sample and hence increases the dielectric constant (semiconducting behavior). With increasing the temperature, the increase of the dielectric constant is slow indicating that, the polarizations become weak.

The variation of loss tangent $(\tan \delta)$ as a function of frequency at temperature range (300$650 \mathrm{~K})$ is shown in Fig. 3. The value of $\tan \delta$ represents the loss of electrical energy into the samples. It is observed from Fig. 3 that the dielectric loss decreases rapidly in the low-frequency region, while the rate of decrease is slow in the middle region and then becomes almost frequency independent in the high-frequency region. Such behavior for ferrites and composites in the low-frequency region is due to the low conductivity of grain boundaries. Due to the lower conductivity, more energy is required for an electron to exchange between $\mathrm{Fe}^{2+}$ and $\mathrm{Fe}^{3+}$ ions; resulting in higher values of $\tan \delta$. In the high-frequency region, which corresponds to the high conductivity of grains, small energy is required for electron transfer between the $\mathrm{Fe}^{2+}$ and $\mathrm{Fe}^{3+}$ ions at the octahedral site $[34,36]$. The value of $\tan \delta$ decreases with the core-shell composites because of a decrease in conductivity of the core-shell. In other words, the dielectric loss decreases with the core-shell due to the presence of inhomogeneities as a result of composite formation in the form of grain structure. From the loss tangent data presented in Fig. 3c, it is easy to notice that the tan $\delta$ of $\mathrm{NiF} @ \mathrm{MgF}$ exhibits a kink in the range of $10 \mathrm{kHz}-3 \mathrm{MHz}$.

It is observed from Fig. 3 that in the $\mathrm{MHz}$ region, all samples exhibit a loss peak following the Debye type of relaxation. This peak is strong for $\mathrm{MgF}$ and $\mathrm{ZnF} @ \mathrm{MgF}$ and weak 
for NiF@MgF. The electric dipoles cannot follow the alternating field instantaneously; some time is needed for the alignment of dipoles with the field [37]. This peak is observed in ferrite materials when the jumping/hopping frequency of electrons/holes among ions becomes equal to the frequency of the applied field, in other words, this peak is resonance phenomena, i.e., maximum electric energy is transferred to the electrons and the loss shoots up at resonance. The maximum peak in the curve of the dielectric loss (tan $\delta)$ vis frequency is obeyed to the following expression [38]:

$$
\omega \tau=1
$$

where $\omega=2 \pi f_{\max }, \tau$ is the relaxation time, and $f_{\max }$ is the maximum frequency. The relaxation time $(\tau)$ and the jumping probability per unit time are related as:

$$
\tau=1 / 2 p
$$

Thus, it is clear that the maxima can be observed when the hopping frequency of electrons between cations ions as in Eq. (9-11) become the same frequency of applied alternating electric field; $f_{\max } \propto \mathrm{p}$.

The variation of dielectric loss ( $\tan \delta$ ) with temperature for all samples in the frequency range $100 \mathrm{~Hz}-8 \mathrm{MHz}$ is shown in Fig.4. The dielectric loss value at low temperatures has a loss peak, particularly the samples $\mathrm{MgF}$, and $\mathrm{NiF} @ \mathrm{MgF}$. The behavior of $\tan \delta$ with temperature is similar to other samples reported by other researchers [36, 39]. The increase in $\tan \delta$ with temperature increases is expected because as the temperature increases the conductivity increases. In other words, the increase in dielectric loss with temperature may be due to a thermally activated relaxation mechanism. Moreover, an increase in the value of dielectric loss around $620 \mathrm{~K}$ for $\mathrm{NiF} @ \mathrm{MgF}$ may be corroborated with ferroelectric-paraelectric phase change, i.e., the transition temperature of $\mathrm{NiF} @ \mathrm{MgF}$.

\subsection{AC Conductivity}

To go further into dielectric results analysis, the ac conductivity vs. frequency plots for

all samples at temperature range 290-650K are presented in Fig. 5. As shown in Fig. 5 it is easy to notice that all samples are frequency and temperature-dependent, and the conductivity value of the $\mathrm{MgF}$ and $\mathrm{ZnF} @ \mathrm{MgF}$ are lower than $\mathrm{NiF} @ \mathrm{MgF}$. Also, the conductivity in all samples exhibits a kink at $3 \mathrm{MHz}$. 
The increase in the ac conductivity with increasing frequency can also be elucidated following Koop's phenomenological model which suppose that the material behaves as a multilayer capacitor. The conductivities observed at the low and high frequencies are due to the grain boundaries and grains, respectively. Additionally, according to the literature [33], observation of such a linear increase in conductivity with frequency can also be associated with the polaron assisted type of electrical conduction. As in Fig. 5, it was observed that the conductivity values in the low frequencies are lower than that of high-frequency values for the three samples at all temperatures operated. In this context, it can be deduced that grain boundaries inhibit the movement of charge carriers. As a result of this effect, there is little hopping between cations and hence the conductivity remains low at low frequencies. When the frequency of the applied field is increased to $\mathrm{MHz}$, grains become more dominant, and hence increasing number of hopping between cations can occur that leads to high conductivity values at high frequencies.

Since a linear increase was observed in the relation of the conductivity with the frequency (see Fig.5), so this relation obeys the dynamical ac power law, which was proposed by Jonscher [40]:

$$
\sigma(\omega)=\mathrm{A} \omega^{S}
$$

where $\omega=2 \pi \mathrm{f}$ is the angular frequency, $\mathbf{A}$ is a constant and has units of $\sigma$, and (s) is dimensionless. The value of $(s)$ can be determined from the slope of $\ln \sigma$ versus $\ln \omega$ plots at room temperature. The value of $(s)$ lies between 0 and 1 as shown in Fig. 6. Literature data [4142] have shown the conductivity mechanism in any material could be understood from the temperature-dependent behavior of $(s)$. In other words, the temperature dependence of $(s)$ gives a critical knowledge about the charge transport mechanism in dielectric substances. To comprehend the electrical conduction mechanism in the materials, different theoretical models have been proposed (regarding frequency and temperature dependence of the exponent $(s)$ ). Theoretical models have been proposed to explain the behavior of the exponent $(s)$ of ferrites. If the frequency exponent $(s)$ is temperature independent but frequency-dependent, the simple quantum mechanical tunneling (QMT) model can be proposed. In contrast, if (s) is temperature dependent, increasing with increasing temperature, the proposing model can be the nonoverlapping small polaron tunneling (NSPT) [43]. For another mechanism for polaron tunneling, called the overlapping large polaron tunneling (OLPT) model [44], the exponent $(s)$ is dependent 
on both frequency and temperature in addition to its decrease from unity with an increase in temperature. For large polarons, $(s)$ continue to decrease with increasing temperature tending to its value predicted by the QMT model for non-overlapping carriers. For small polarons (SP), (s) exhibits a minimum at a certain temperature and subsequently increases with an increase in temperature. In the correlated barrier hopping $(\mathrm{CBH})$ model [42] a temperature-dependent exponent $(s)$ is predicted, where $(s)$ decreases with the increase in temperature.

The observed variation of $(s)$ with temperature as shown in Fig.6, maybe due to different mechanisms of conducting and dielectric losses at different temperatures of the core-shell composites. Here two different values of $(s)$ for each sample, i.e., in the frequency range $100 \mathrm{~Hz}$ $1 \mathrm{MHz}$ value $\left(\boldsymbol{s}_{\mathbf{L}}\right)$ and in the high-frequency range $1-8 \mathrm{MHz}$ other value $\left(\boldsymbol{s}_{\mathbf{H}}\right)$. For the samples $\mathrm{MgF}$ and $\mathrm{ZnF} @ \mathrm{MgF}$, it clear that the exponent $\left(\boldsymbol{s}_{\mathbf{L}}\right)$ has variation behavior with temperature, it is decreased in the low temperature and then increase and then decreased again, so the samples signified the coexistence of two SP and CBH models. But for the NiF@ MgF the exponent $\left(\boldsymbol{s}_{\mathbf{L}}\right)$ is slowly increased with temperature, so it tends to propose the SP model of conduction. But for the exponent $\left(\boldsymbol{s}_{\mathbf{H}}\right)$ the behavior is different, i.e., the $\mathrm{CBH}$ model for the samples $\mathrm{MgF}$ at high temperature, but at low temperature obeys to the model QMT and the NiF@MgF the model SP is starting then QMT, whereas the ZnF@MgF tends to propose the QMT model of conduction. This variation of the exponent $(s)$ with temperature is similar to $\mathrm{BaTiO}_{3} / \mathrm{NiZnFe}_{2} \mathrm{O}_{4}$ [45]. On the other hand, as the frequency exponent value of the $\mathrm{NiF} @ \mathrm{MgF}$ composites reaches 0.6 with increasing temperature, the hopping of the mobile charges is becoming faster [33].

It is clear that from Fig 7 the curves of $\log (\sigma)$ versus 1000/T could be divided into three regions, as I, II, and III. As is seen in Fig. 7, at first $\sigma_{\text {ac }}$ values of all samples, increase up to a certain temperature denoted as $\boldsymbol{T}_{s}$, then start to decrease up to another critical temperature $\boldsymbol{T}_{\boldsymbol{m}}$ and finally increases with increasing temperature may be due to a ferrimagnetic-paramagnetic transition or the Curie temperature $\left(\boldsymbol{T}_{c}\right)$ of the all samples. $\boldsymbol{T}_{s}$ and $\boldsymbol{T}_{\boldsymbol{m}}$ temperatures correspond to the transition temperatures from semiconducting to metallic and metallic to semiconducting regions, respectively. The value of $\boldsymbol{T}_{\boldsymbol{s}}$ temperature is different for each sample $\mathrm{MgF}, \mathrm{ZnF} @ \mathrm{MgF}$, and NiF@MgF 343, 333, and 338 K respectively, while the value of $\boldsymbol{T}_{\boldsymbol{m}}$ is the same for the pure $\mathrm{Mg}$ ferrite and the $\mathrm{ZnF} @ \mathrm{MgF}$ core-shell $\left(\boldsymbol{T}_{\boldsymbol{m}}=433 \mathrm{~K}\right)$, whereas the core-shell NiF@MgF has $\boldsymbol{T}_{\boldsymbol{m}}=443 \mathrm{~K}$. Also, the Curie temperature $\boldsymbol{T} \boldsymbol{c}$ (as presented in Table 1) occurs for pure $\mathrm{Mg}$ ferrite, and the $\mathrm{ZnF} @ \mathrm{MgF}$ core-shell is the same temperature $(503 \mathrm{~K})$ but for $\mathrm{NiF} @ \mathrm{MgF}=653 \mathrm{~K}$. 
To determine the origin of the semiconducting and metallic conduction in all the samples as many cases of ferrites $[33,46]$, the charge transport phenomenon of hopping of $\boldsymbol{d}$ electrons of transition metal ions. The electrostatic interactions between anion and cation electrons cause splitting of $\mathbf{3} \boldsymbol{d}$-level into more stable triply degenerate $\boldsymbol{t}_{2 \boldsymbol{g}}$ level and less stable doubly degenerate $\boldsymbol{e}_{\boldsymbol{g}}$ level [47]. According to Anderson [48] and Goodenough [49], there are two interactions in ferrites, cation-anion-cation and cation-cation interactions. Both interactions can be simultaneously presented. As temperature raising in the low region, the cation-anion-cation interactions must be stronger, in this case, the materials have semiconductor or insulator behavior. However, if cations of the same element but different valence are simultaneously present, the materials may have metallic type $\sigma-T$ character below a transition temperature [49]. In the case of strong cation-cation interaction, these materials have a metallic behavior and may become semiconductors at low temperatures. As the temperature is increased from $\boldsymbol{T}_{\boldsymbol{s}}$ to $\boldsymbol{T}_{\boldsymbol{m}}$, the shell and core spin align. Hence, the localized states become delocalized and conducting channels, which are responsible for the metallic conduction, constitute. This may be due to the reduced cation and anion content in the composites. Finally, when the temperature is raised from $\boldsymbol{T}_{\boldsymbol{m}}$ to $433 / 443 \mathrm{~K}$, delocalized electrons return their localized levels due to the occurrence of magnetic disorder which leads to the semiconducting nature for each sample.

Another explanation of the semiconducting and metallic conduction behavior, the combination between two different materials that have different properties to yield a new compound; the second material may lead to an enhancement or non-enhancement of the properties of the new compound, owing to the type of interaction between the two materials [50]. Therefore, the $\sigma-T$ character for all nanocomposites can be explained based on the exchange interactions between the NF and MF in NF@MF and between ZF and MF in ZF@MF. As shown in Fig. 7, the semiconducting-metallic behavior of $\mathrm{MgF}$ and $\mathrm{NiF} @ \mathrm{MgF}$ is stronger than $\mathrm{ZnF} @ \mathrm{MgF}$. Also, the transition temperature of $\mathrm{NiF} @ \mathrm{MgF}$ nanocomposite is lower than that of $\mathrm{NF}\left(\boldsymbol{T}_{\boldsymbol{C}}=850 \mathrm{~K}\right)[46]$ and higher than that of $\mathrm{MgF}\left(\boldsymbol{T}_{\boldsymbol{C}}=503 \mathrm{~K}\right)$. As for $\mathrm{ZnF} @ \mathrm{MgF}$, the situation is different where the transition temperature is the same as $\mathrm{MgF}=503 \mathrm{~K}$. This indicates that the effect of $\mathrm{MgF}$ on both $\mathrm{NiF}$ and $\mathrm{ZnF}$ is positive, because the net conduction of $\mathrm{NiF} @ \mathrm{MgF}$ will be increased and decreased the transition temperature, and the net conduction and the transition temperature of $\mathrm{ZnF} @ \mathrm{MgF}$ are increased concerning $\mathrm{ZnF}$. This is in agreement with the magnetic behavior of $\mathrm{NiF} @ \mathrm{MgF}$ and $\mathrm{ZnF} @ \mathrm{MgF}$ core-shell [4]. 
The ac conductivity is a thermally activated process, dependent on the temperature as shown in Fig. 7. The ac conductivity shows the activated temperature dependence as Arrhenius relation

$$
\sigma=\mathrm{A} \exp ^{\mathrm{Ea} / \mathrm{kT}}
$$

where $\mathrm{A}$ is constant, $\mathrm{E}_{\mathrm{a}}$ is the activation energy, which is the energy needed to jump an electron from an ion to a neighboring ion, so giving rise to the electrical conductivity, $\mathrm{k}$ is Boltzmann's constant, and $\mathrm{T}$ is the absolute temperature. We can obtain the activation energy by plotting $\log \sigma$ versus $1000 / T$, the slope of the linear parts will be equal to $\left(\mathrm{E}_{a} / k\right)$. The activation energies for these processes are calculated and presented in Table 1. It is observed that the value of the activation energies is varying with temperature due to the varieties of the conduction mechanism.

Table 1: Electric and magnetic susceptibility parameters.

\begin{tabular}{|c|c|c|c|c|c|c|c|c|}
\hline Sample & $\mathbf{T}_{\mathbf{C}}(\mathbf{K})$ & $\begin{array}{c}\mathbf{E}_{\mathbf{a}} \mathbf{I} \\
(\mathbf{e V})\end{array}$ & $\begin{array}{c}\mathbf{E}_{\mathbf{a}} \mathbf{I I} \\
(\mathbf{e V})\end{array}$ & $\begin{array}{c}\mathbf{E}_{\mathbf{a}} \mathbf{I I I} \\
(\mathbf{e V})\end{array}$ & $\mathbf{T}_{\chi}(\mathbf{K})$ & $\boldsymbol{\theta}(\mathbf{K})$ & $\mathbf{C}$ & $\begin{array}{c}\mu_{\text {eff }} \\
\text { Bg.M. }\end{array}$ \\
\hline NiF@MgF & 503 & 1.3 & 0.9 & 0.13 & 350 & 349 & 0.57 & 2.1 \\
\hline ZnF@MgF & 653 & 0.1 & 0.13 & 0.12 & 426.5 & 424 & 9.2 & 8.56 \\
\hline
\end{tabular}

\subsection{The magnetic susceptibility}

The magnetic susceptibility measurement is an interesting technique for determining phase boundaries in magnetic systems as there is a distinct change in magnetic properties during a phase transition. The temperature dependence of the magnetization $\mathrm{M}(\mathrm{T})$ for all samples is shown in Fig. 8. The temperature plots are obtained in a magnetic field of $0.8 \mathrm{mT}$ in the range of 300-500K. The data reveals the normal trend of ferrimagnetic materials; $\mathrm{M}(\mathrm{T})$ decreased with the temperature reaching the paramagnetic region where the magnetocrystalline anisotropy ceased, and the magnetization drops at the well-known Curie point. In the paramagnetic region, the thermal energy increased the entropy and randomized the spin orientations where the forces overcome the magnetocrystalline energy. Also notice that, the magnetization of the core-shell $\mathrm{ZnF} @ \mathrm{MgF}$ higher than that of the pure MgF nanoferrite, which confirmed the previous work [4]. The increase in the magnetization for nanocomposites $\mathrm{ZnF} @ \mathrm{MgF}$ at the expense of $\mathrm{MgF}$ can be attributed to two factors: 
- The decrease of the canting angle between the moments in the B-site leads to an increase in the magnetization [51].

- The increase in the magnitude of the total magnetic moments in the B-site leads to the magnetization increase.

These two factors seem to compete with each other and cause an increase in the magnetization for $\mathrm{ZnF} @ \mathrm{MgF}$ at the expense of $\mathrm{MgF}$. Therefore, the sample $\mathrm{ZnF} @ \mathrm{MgF}$ is a ferrimagnetic substance.

From the experimental data $\mathrm{M}(\mathrm{T})$ as shown in Fig. 8, with increasing the temperature, a smoothly drop-in the magnetization occurred. The temperature at which magnetization drops is considered as the Curie temperature (Here we will name the Curie temperature of the magnetization by $\boldsymbol{T}_{\boldsymbol{C} \boldsymbol{m}}$ to distinguish it from the Curie temperature of the dielectric conductivity $\boldsymbol{T}_{\boldsymbol{C}}$ ). In other words, the smooth transition from ferrimagnetic to paramagnetic at the Curie temperature $\boldsymbol{T}_{\boldsymbol{C} \boldsymbol{m}}$ can be used as a measure of the degree of compositional homogeneity in all samples [52]. The Curie temperature $\left(\boldsymbol{T}_{\boldsymbol{C m}}\right)$ is an important magnetic property and is a compositional dependent parameter. The Curie temperature $\left(\boldsymbol{T}_{\boldsymbol{C m}}\right)$ was calculated from the plot of the first derivative of magnetization (dM/dT) versus temperature (T) as shown inset of Fig. 8 and listed in Table 1. The transition temperature $\boldsymbol{T}_{\boldsymbol{C} \boldsymbol{m}}$ for $\mathrm{MgF}, \mathrm{ZnF} @ \mathrm{MgF}$, and $\mathrm{NiF} @ \mathrm{MgF}$ is $350 \mathrm{~K}$, $426.5 \mathrm{~K}$, and $483 \mathrm{~K}$ respectively, which is lower than the $\mathrm{NiF}(865 \mathrm{~K})$, and $\mathrm{MgF}(648 \mathrm{~K})$ [53]. This may be due to the influence of the interaction between the core $(\mathrm{MgF})$ and the shell $(\mathrm{NiF}$ or $\mathrm{ZnF})$ on the magnetic transition temperature $\left(\boldsymbol{T}_{\boldsymbol{C}}\right)$. In other words, the mutual effect between $\mathrm{MgF}$ and $\mathrm{NiF}$ or $\mathrm{ZnF}$ leads to a lower magnetic transition temperature. The same behavior has also been observed in many compounds of nanoparticles [52, 54-55]. Moreover, it was observed that the $\boldsymbol{T}_{\boldsymbol{C} \boldsymbol{m}}$ and $\boldsymbol{T}_{\boldsymbol{C}}$ values were different for all samples. From this work, it can be understood that the magnetic and dielectric properties will be varied significantly due to the existed magnetic cations and electric charges for both the core and the shell, respectively. Similar variations of the TCm and TC values were noticed in the literature [41, 56-57].

Figure 9 shows the relation between the reciprocal magnetic susceptibility $\left(\chi_{M}{ }^{-1}\right)$ and the temperature $(\mathrm{T})$ for all investigated samples. The relation obeyed the well-known Curie-Weiss law in the paramagnetic region. So the experimental effective magnetic moments $\mu_{\text {eff }}$ and the 
Curie Weiss constant $(\Theta)$ values can be calculated from the plot of $\chi_{M^{-1}}$ versus $T$ using the relation:

$$
\mu_{\text {eff }}=2.82787 \sqrt{ } \mathrm{C}
$$

where $\mathrm{C}$ is the Curie constant equal to the slope of the line in the paramagnetic region and presented in Table 1. The variation of $\mu_{\text {eff }}$ with the substituted ions depends on its grain size. Where the decrease of the grain size tends generally to decrease the magnetization [58]. Also, the net magnetic moment is strongly dependent on the $\mathrm{Fe}^{3+}$ ions on the $(\mathrm{B})$ sites. This means that the effect of the magnetic moment of $\mathrm{MgF}$ on the magnetic moment of $\mathrm{ZnF}$ is positive so the net magnetic moment of ZF@MF will be increased. In other words, the mutual effect between $\mathrm{MgF}$ and $\mathrm{ZnF}$ leads to an increase in the net magnetic moment of ZF@MF.

The Curie Weiss constant $(\Theta)$ values equal to the cross of the slope with the $x$-axis in Fig. 9 and listed in Table 1. The Curie-Weiss constant $(\Theta)$ was found to possess large +ve values pointing to perfect ferrimagnetic character. The rise in $\Theta$ values with $\mathrm{NiF} @ \mathrm{MgF}$ assures the enhanced ferrimagnetic order of the core-shell from the increase in the ordered of the $(\mathrm{MgF})$ at the expense of the $(\mathrm{NiF})$. This indicates all samples have magnetic ferrimagnetic ordering in the temperature range $300-500 \mathrm{~K}$. Also, the values of the Curie Weiss constant $(\Theta)$ for all samples are closed to the values of the Curie temperature of the magnetization $\left(\boldsymbol{T}_{\boldsymbol{C m}}\right)$.

\section{Conclusion}

The mutual effect between $\mathrm{ZnF}$ and $\mathrm{MgF}$ or $\mathrm{NiF}$ and $\mathrm{MgF}$ improved the physical properties of $\mathrm{MgF}, \mathrm{NiF}$, and $\mathrm{ZnF}$. When studying the dielectric constant under the influence of temperature $(300-650 \mathrm{~K})$ and frequency $(100 \mathrm{~Hz}-8 \mathrm{MHz})$, it was found that the mutual effect increases the space charge polarization and contributes to the dielectric constant. From the previous work [4] and the present work, we can conclude that the sample that possesses a large grain size, will be has a higher value of dielectric constant. Also, the value of the loss of electrical energy $(\tan \delta)$ decreases with the core-shell composites. Besides, the conduction mechanism varies between SP, $\mathrm{CBH}$, and QMT models according to the temperature and the frequency, so the conduction behavior of all samples is semiconductor-metallic. The experimental results of the ac electrical conductivity found that the transition temperature of a ferroelectric-paraelectric is lower than the transition temperature of the alone components of the core-shell. The mutual effect in the magnetic properties is more strong, where all samples have 
magnetic ordering in the temperature range $300-500 \mathrm{~K}$. The novelty in this work is an unexpected behavior of ZnF@MgF which possesses magnetization higher than the pure ferrite phase $\left(\mathrm{MgFe}_{2} \mathrm{O}_{4}\right)$, and Curie temperature $\left(\boldsymbol{T}_{\boldsymbol{C} m}\right)$ higher than the room temperature. Therefore, the sample ZnF@MgF is a ferrimagnetic substance.

\section{Declaration of interests}

The authors declare that they have no known competing financial interests or personal relationships that could have appeared to influence the work reported in this paper.

\section{Data Availability Statements}

The data that support the findings of this study are available from the corresponding author upon reasonable request.

\section{References}

1] Anju Ahlawat, Azam Ali Khan, Pratik Desmukh, Mandar M. Shirolkar, Jieni Li, Haiqian Wangd, S. Satapathy, A.K. Karnal, Materials Letters 261 (2020) 127082.

2] A. Ahlawat, S. Satapathy, M.M. Shirolkar, J. Li, A.A. Khan, P. Deshmukh, H. Wang, R.J. Choudhary, A.K. Karnal, ACS Appl. Nano Mater. 1 (2018) 3196-3203.

3] J.S. Andrew, J.D. Starr, M.A.K. Budi, Scripta Mater. 74 (2014) 38-43.

4] Kh. Roumaih, M. Yehia, H. E. Hassan, J. Inorg. and Organ. Polym. and Mater. (2020) 30:3132-3142.

5] U. Naresh, R.J. Kumar, K.C.B. Naidu, Mater. Chem. Phys. 236 (2019) 121807.

6] U. Naresh, R.J. Kumar, K.C.B. Naidu, Ceram. Int. 45 (2019) 7515-7523.

7] T.A. Taha, A.A. Azab, M.A. Sebak, J. Mol. Struct. 1181 (2019) 14-18.

8] D.K. Dinkar, B. Das, R. Gopalan, B.S. Dehiya, Chem. Phys. 218 (2018) 70-76.

9] M.A. Almessiere, Y. Slimani, S. Güner, A. Baykal, I. Ercan, J. Rare Earths 37 (2019) 871-878.

10] S.V. Bhosale, P.S. Ekambe, S.V. Bhoraskar, V.L. Mathe, Appl. Surf. Sci. 441 (2018) 724-733.

11] K. Kombaiah, J.J. Vijaya, L.J. Kennedy, K. Kaviyarasu, Mater. Chem. Phys. 221 (2019) 11-28. 
12] W.E. Pottker, R. Ono, M.A. Cobos, A. Hernando, J.F.D.F. Araujo, A.C.O. Bruno, F. A. La Porta, Ceram. Int. 44 (2018) 17290-17297.

13] N. Raghu Ram, M. Prakash, U.N. Naresh, Suresh Kumar, T. Sofi Sarmash, T. Subbarao, R. Jeevan Kumar, G. Ranjith Kumar, K. Chandra Babu Naidu, J. Supercond. Nov. Magnetism 31 (2018) 1971-1979.

14] K.C.B. Naidu, W. Madhuri, Bull. Mater.Sci. 40 (2017) 417-425.

15] S. Akbari, S.M. Masoudpanah, S.M. Mirkazemi, N. Aliyan, Ceram. Int. 43 (2017) 62636267.

16] J. Kurian, M.J. Mathew, J. Magn. Magn Mater. 451 (2018) 121-130.

17] K.C.B. Naidu, S.R. Kiran, W. Madhuri, Mater. Res. Bull. 89 (2017) 125-138.

18] M. Bini, C. Tondo, D. Capsoni, M.C. Mozzati, B. Albini, P. Galinetto, Mater. Chem. Phys. 204 (2018) 72-82.

19] Xinyang Zhang, Zhaofeng Chen, Cao Wu, Junxiong Zhang, Fei Wang, Solvothermal, Chemistry Physics Letters 732 (2019) 136647.

20] V.I. Popkov, V.P. Tolstoy, V.G. Semenov, J. All and Com. 813 (2019) 152179.

21] Y. Ge, Z. Wang, M. Yi, L. Ran, Trans. Nonferrous Metals Soc. China 29 (2019) 15031509.

22] K.C.B. Naidu, N.S. Kumar, G.R. Kumar, S.N. Kumar, Journal of Australian Ceramic Society 55 (2019) 541-548.

23] K.C.B. Naidu, W. Madhuri, IEEE Trans. Magn. 54 (2018) 2300808.

24] K.C.B. Naidu, W. Madhuri, Phase Transitions 90 (2017) 847-862.

25] T. Vidya Sagar, T. Subba Rao, K. Chandra Babu Naidu, Mater. Chem. and Phys. 258 (2021) 123902.

26] J. C. Maxwell, Electricity and Magnetism, Oxford University Press, 1973.

27] K.W. Wagner, Ann. Phys. 40 (1993) 818.

28] C. Koops, Phys. Rev. 83 (1951) 121.

29] R. Tadi, Y. I. 1Kim, D. Sarkar, C. G. Kim, K. S. Ryu, J. Magn. Magn. Mater. 323 (2011) 564-568.

30] S.B. Reddy, K.P. Rao, M.S.R. Rao, J. All and Com.. 509 (2011) 1266-1270. 
31] Vandana Kuldeep, Oroosa Subohi, Rajnish Kurchania, Appl. Phys A (2019) 125:631.

32] Anil S. Gaikwad, R.H. Kadam, Sagar E. Shirsath, Santosh R. Wadgane, Jyoti Shah, R.K. Kotnala, A.B. Kadam, J. All and Com. 773 (2019) 564e570. https://doi.org/10.1016/j.jallcom.2018.09.209.

33] Zeynep Güven Özdemir, Mehmet Kılıç, Yaşar Karabul, Banu Süngü Mısırlığlu, Öznur Çakır, and Naime Didem Kahya, J. Electroceramics (2020) 44:1-15. https://doi.org/10.1007/s10832-019-00194-3.

34] Seema Joshi, Manoj Kumar, Sandeep Chhoker, Arun Kumar, Mahavir Singh, J. Mag. and Mag. Mat 426 (2017) 252-263. http://dx.doi.org/10.1016/j.jmmm.2016.11.090

35] R. Grigalaitis, M. M. Vijatović Petrović, J. D. Bobić, A. Dzunuzovic, R. Sobiestianskas, A. Brilingas, B. D. Stojanović, J. Banys, Ceram Inter. 40 (2014) 6165-6170.

36] Rubiya Samad, Mehraj ud Din Rather, Basharat Want, J. All. and Com. 715 (2017) 4352.

37] M.K.H. Bhuiyan, M.A. Gafur, M.N.I. Khan, A.A. Momin, A.K.M. Akther Hossain, Mater. Sci. Appl. 8 (2017) 64-84.

38] Poonam Pahuja, R.K. Kotnala, R.P. Tandon, J. All. and Com. 617 (2014) 140-148. http://dx.doi.org/10.1016/j.jallcom.2014.07.204.

39] B Want, Mehraj ud Din Rather, Rubiya Samad, J Mater Sci: Mater Electron (2016) 27:5860-5866, DOI 10.1007/s10854-016-4503-8.

40] A.K. Jonscher, J. Phys. D. Appl. Phys. 32, R57 (1999)

41] B.M. Greenhoe, M.K. Hassan, J.S. Wiggins, K.A. Mauritz, J. Polym. Sci. B Pol. Phys., 54 (2016) 1918-1923.

42] V. Thakur, A. Singh, A.M. Awasthi, L. Singh, AIP Advances, 5 (2015) 087110.

43] A. Ghosh, Phys. Rev. B 41 (1990) p.1479.

44] R. Long, Adv. Phys. 31 (1982) p.553.

45] Mirjana M. Vijatovic Petrovic, Adis Dzunuzovic, Jelena D. Bobic, Nikola Ilic, Ivan Stijepovic, Biljana D. Stojanovic, Processing and Application of Ceramics 14 (2020) 918.

46] Kh. Roumaih, J. All. and Com. 465 (2008) 291-295. 
47] I. Bunget, M. Popescu, Physics of Solid Dielectrics, (Elsevier, New York, 1984).

48] P.W. Anderson, Phys. Rev. 79 (1950) 350.

49] J.B. Goodenough, Phys. Rev. 6 (1960) 1442.

50] A. Quarta, C. Piccirillo, G. Mandriota, R. Di Corato, Materials 12, 139 (2019). https ://doi.org/10.3390/ma120 10139.

51] R.G. Kulkarini, V.U. Patial, J. Mater. Sci. 17, 843 (1982)

52] Kh. Roumaih, J. Molec. Struc. $1004 \quad$ (2011) 1-7. http://dx.doi:10.1016/j.molstruc.2011.06.007.

53] Naglaa M. Sadik, A. A. Sattar, M. M. Rashad, H. M. Elsayed, SN Applied Sciences (2020) 2:620, https://doi.org/10.1007/s42452-020-2450-8.

54] A. Franco, F.L.A. Machado, V.S. Zapf, J. Appl. Phys. 110, 053913 (2011), https://doi.org/10.1063/1.3626931

55] R. Topkaya, U. Kurtan, A. Baykal, H. So“zeri, M. S. Toprak, J Inorg. Organomet. Polym. (2013) 23:592-598.

56] K.C.B. Naidu, W. Madhuri, Mater. Chem. Phys. 181 (2016) 432-443.

57] K.C.B. Naidu, W. Madhuri, Int. J. Appl. Ceram. Technol. 13 (2016) 1090-1095.

58] A. Alarifi, N.M. Deraza, S. Shaban, J. Alloys Compd. 486, 501-506 (2009). 


\section{Figure captions}

Figure 1: Frequency dependence of $\varepsilon$ at different temperatures for a) $\mathrm{MgF}, \mathrm{b}) \mathrm{ZnF} @ \mathrm{MgF}$ and c) $\mathrm{NiF} @ \mathrm{MgF}$.

Figure 2: Temperature dependence of $\varepsilon$ at different frequencies for a) $\mathrm{MgF}$, b) $\mathrm{ZnF} @ \mathrm{MgF}$ and c) $\mathrm{NiF} @ \mathrm{MgF}$.

Figure 3: Frequency dependence of tan $\delta$ at different temperatures for a) $\mathrm{MgF}$, b) $\mathrm{ZnF} @ \mathrm{MgF}$ and c) NiF@MgF.

Figure 4: Temperature dependence of tan $\delta$ at different frequencies for a) $\mathrm{MgF}, \mathrm{b}$ ) $\mathrm{ZnF} @ \mathrm{MgF}$ and c) NiF@MgF.

Figure 5: Frequency dependence of $\log (\sigma)$ at different temperatures for a) $\mathrm{MgF}$, b) $\mathrm{ZnF} @ \mathrm{MgF}$ and c) NiF@MgF.

Figure 6: the exponent $(\boldsymbol{s})$ versus $\mathrm{T}(\mathrm{K})$.

Figure 7: The Conductivity $\log (\sigma)$ versus $1000 / \mathrm{T}$ for a) $\mathrm{MgF}$, b) $\mathrm{ZnF} @ \mathrm{MgF}$ and c) $\mathrm{NiF} @ \mathrm{MgF}$.

Figure 8: Temperature dependence of the magnetization for a) $\mathrm{MgF}$, b) $\mathrm{ZnF} @ \mathrm{MgF}$ and c) $\mathrm{NiF} @ \mathrm{MgF}$.

Figure 9: Temperature dependence of the $\chi_{\mathrm{m}^{-1}}$ for a) $\mathrm{MgF}$, b) $\mathrm{ZnF} @ \mathrm{MgF}$ and c) $\mathrm{NiF} @ \mathrm{MgF}$. 


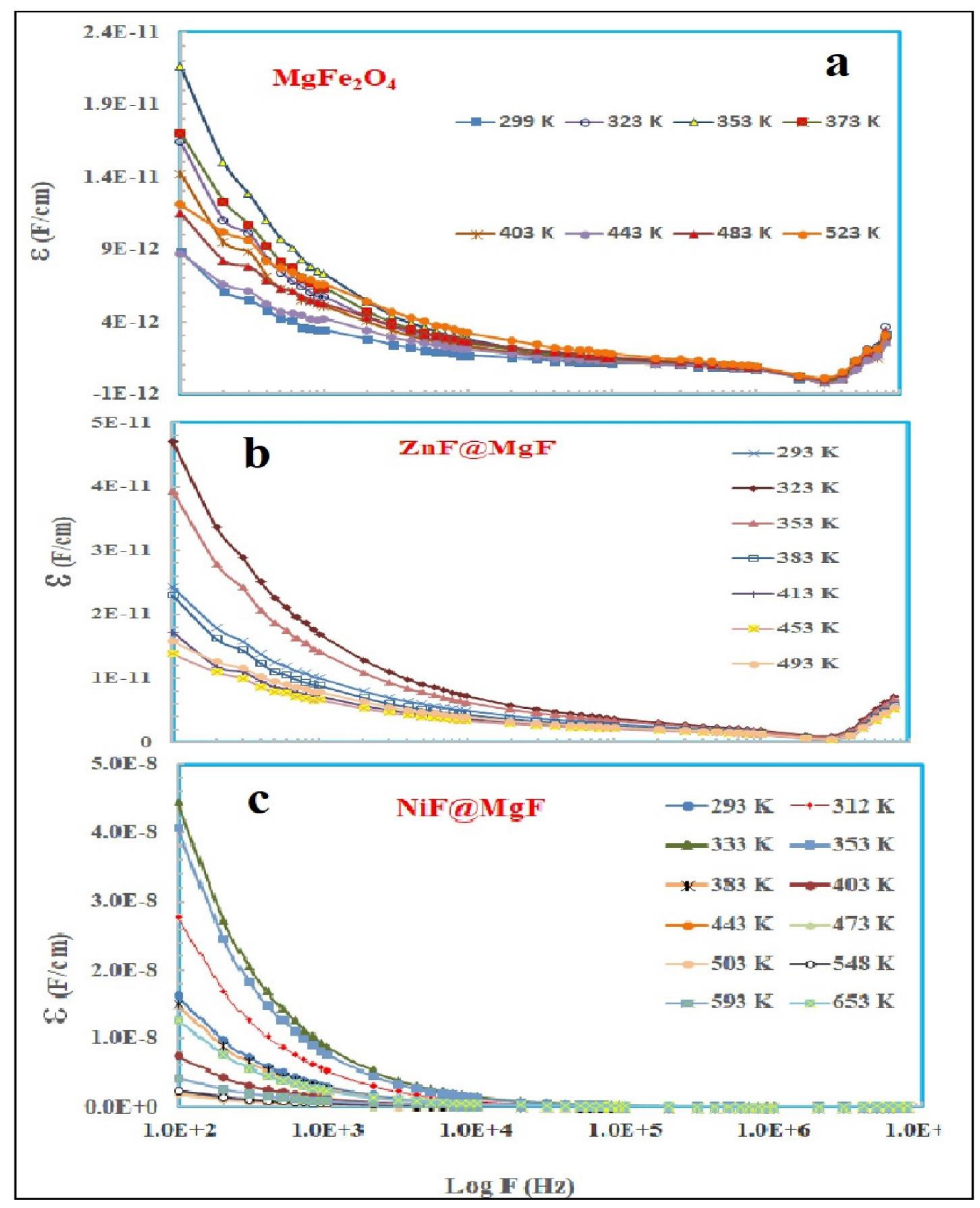

Fig 1. 


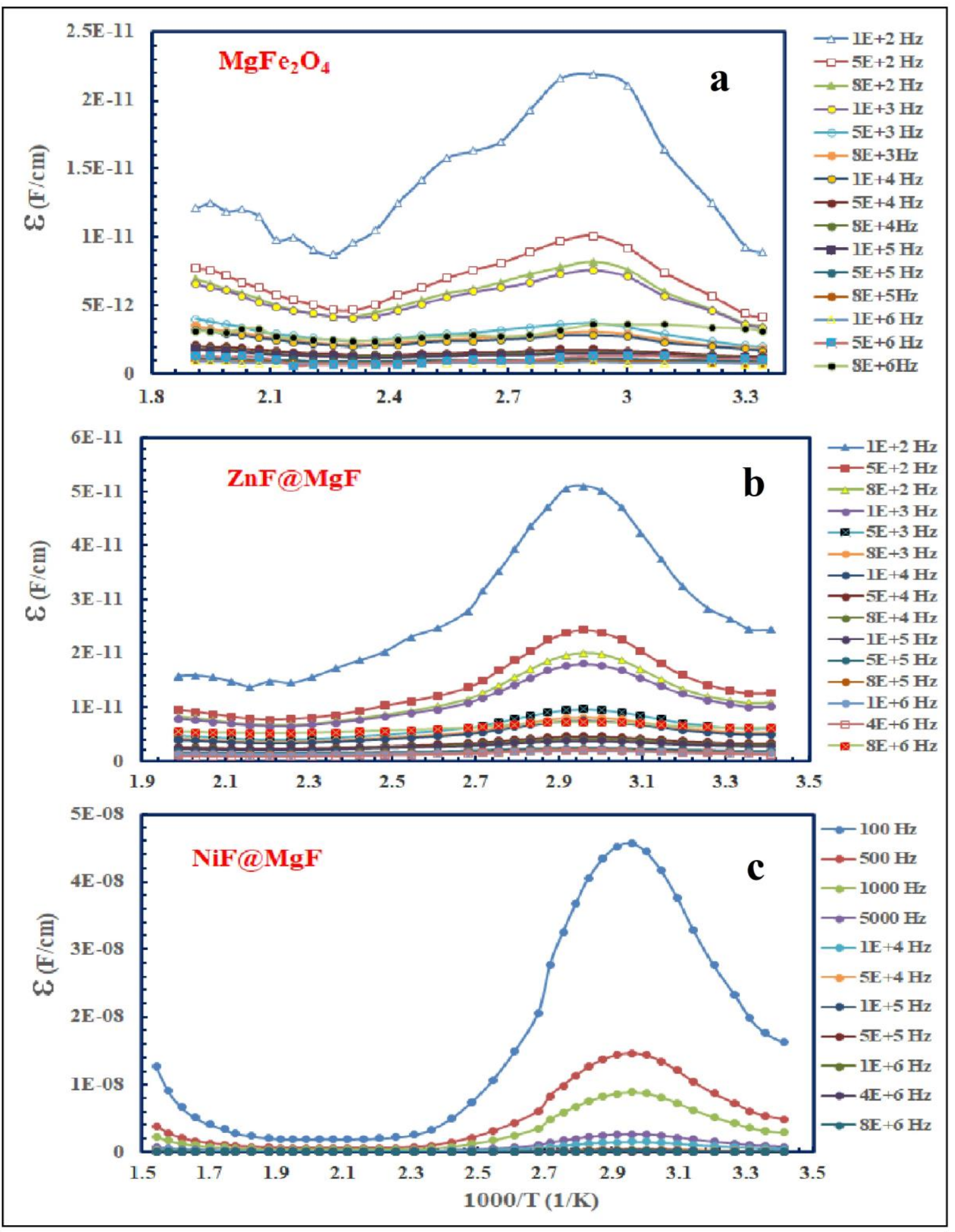

Fig 2. 


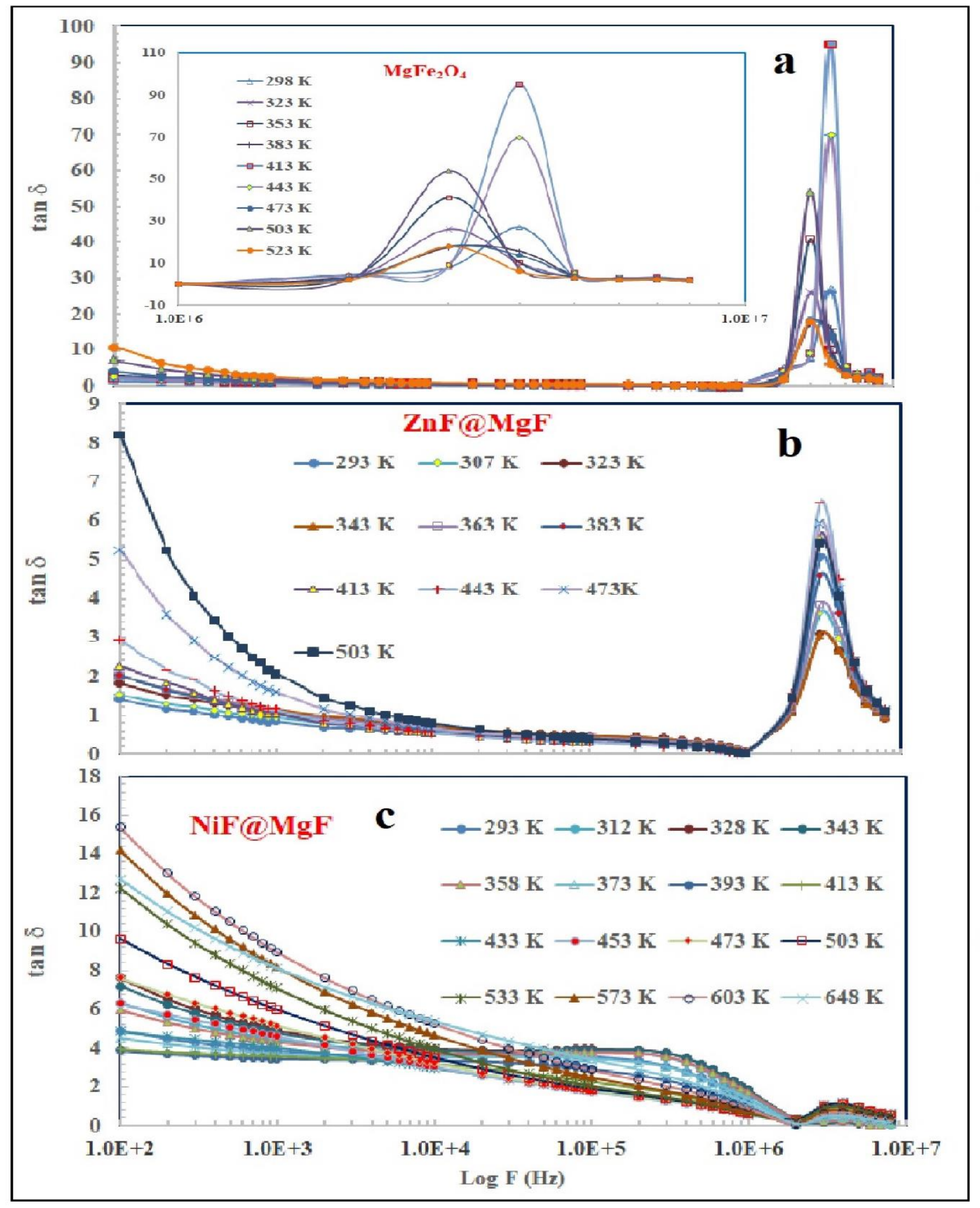

Fig 3 


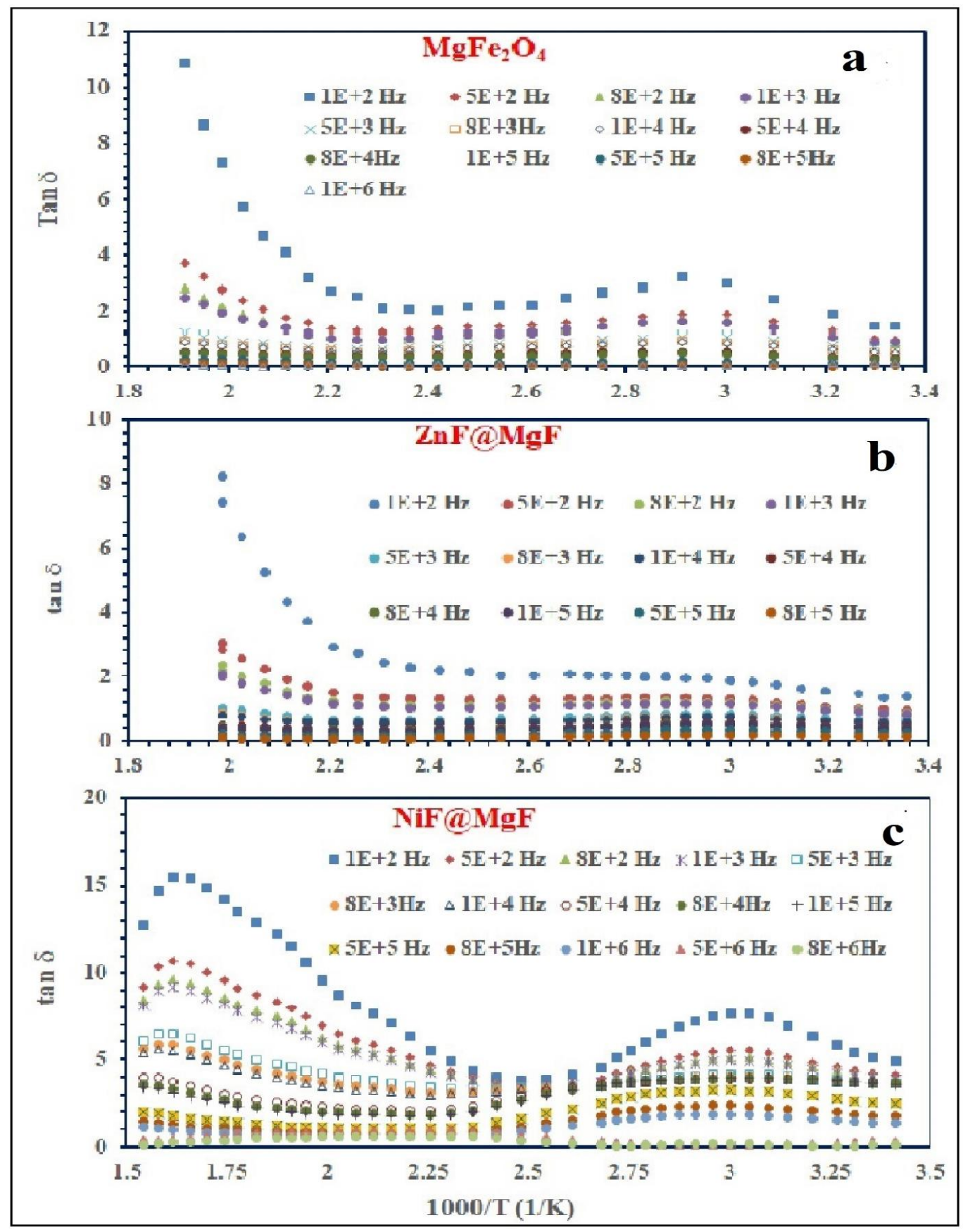

Fig 4. 


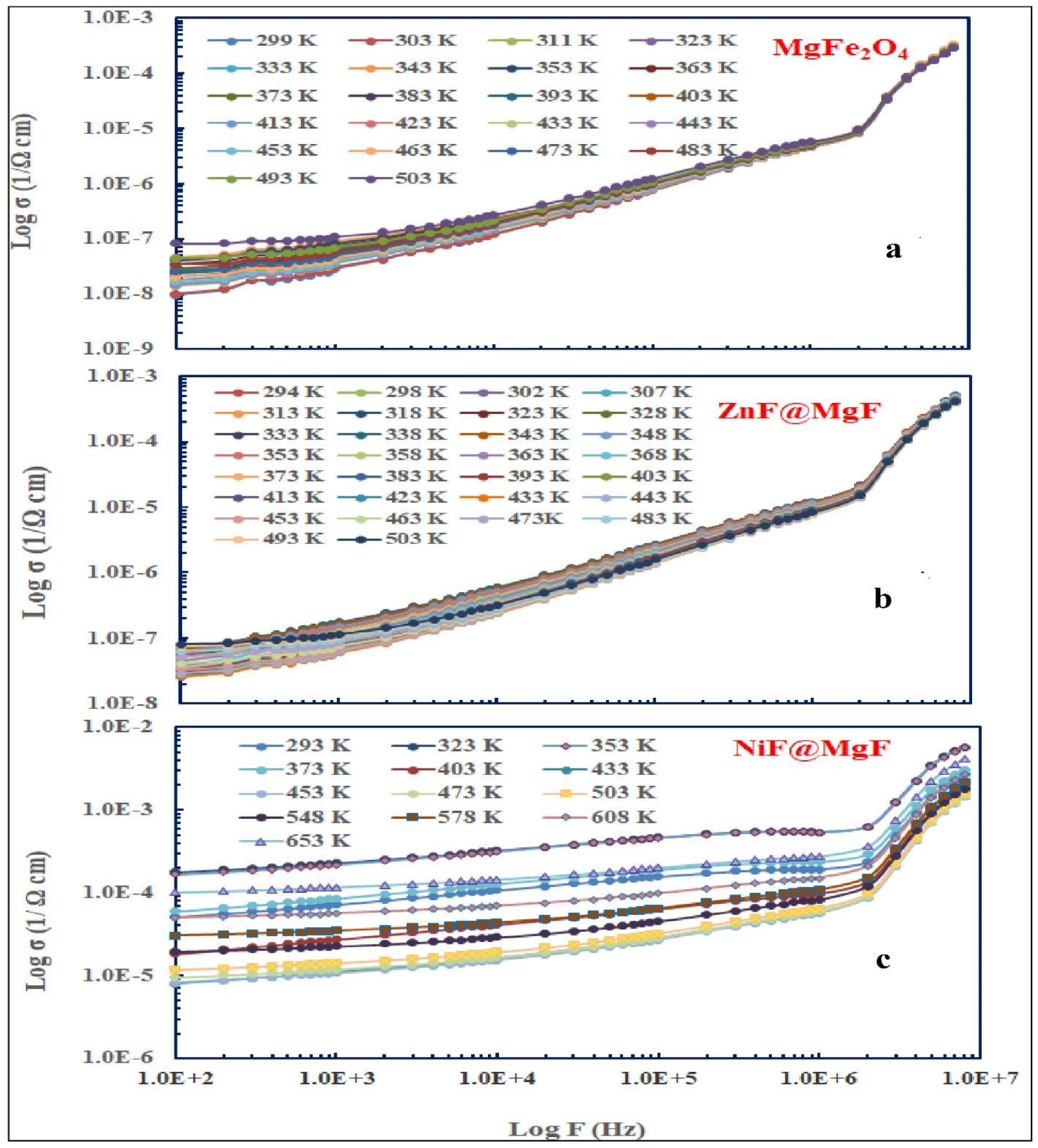

Fig 5. 


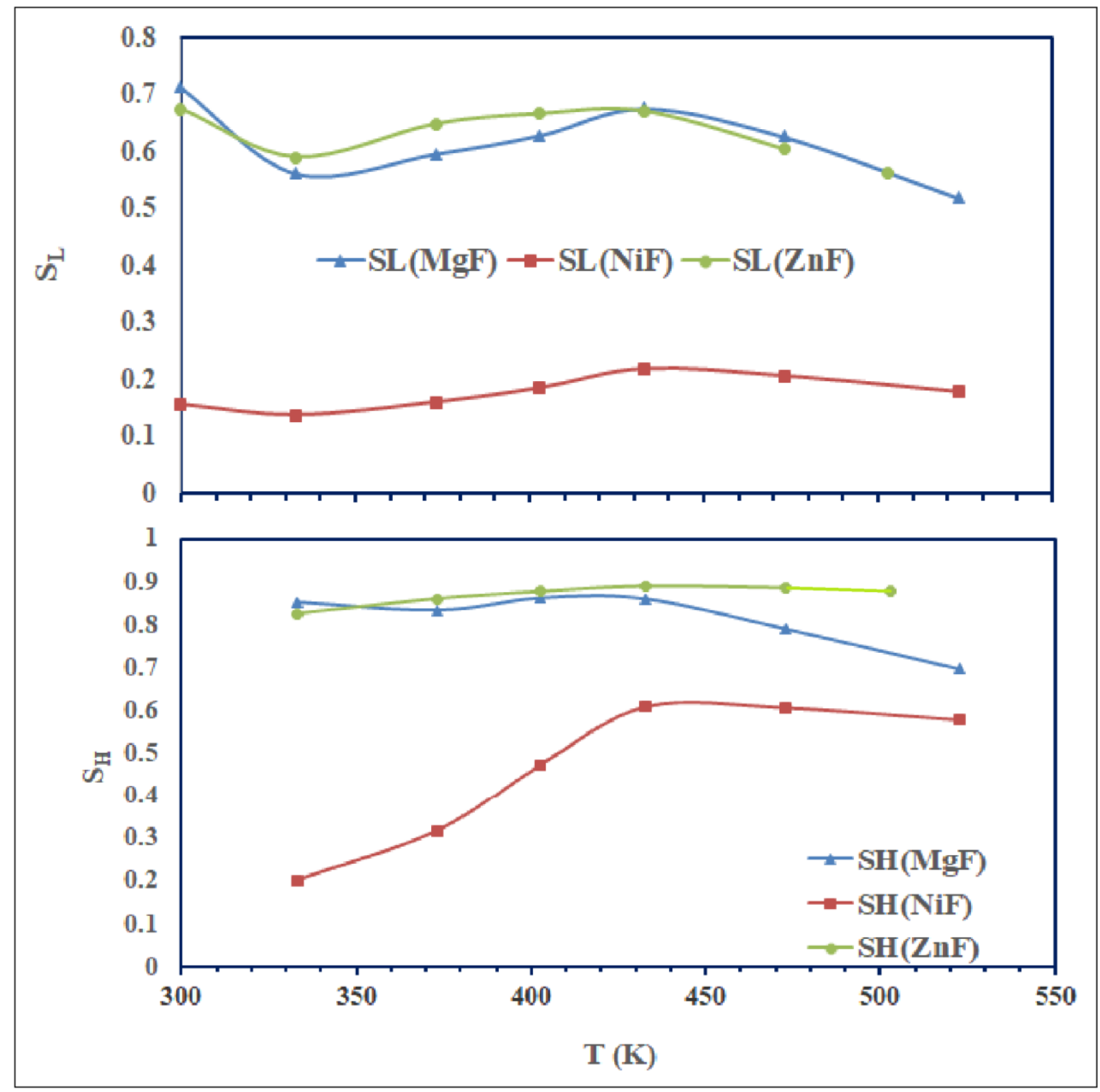

Fig 6 


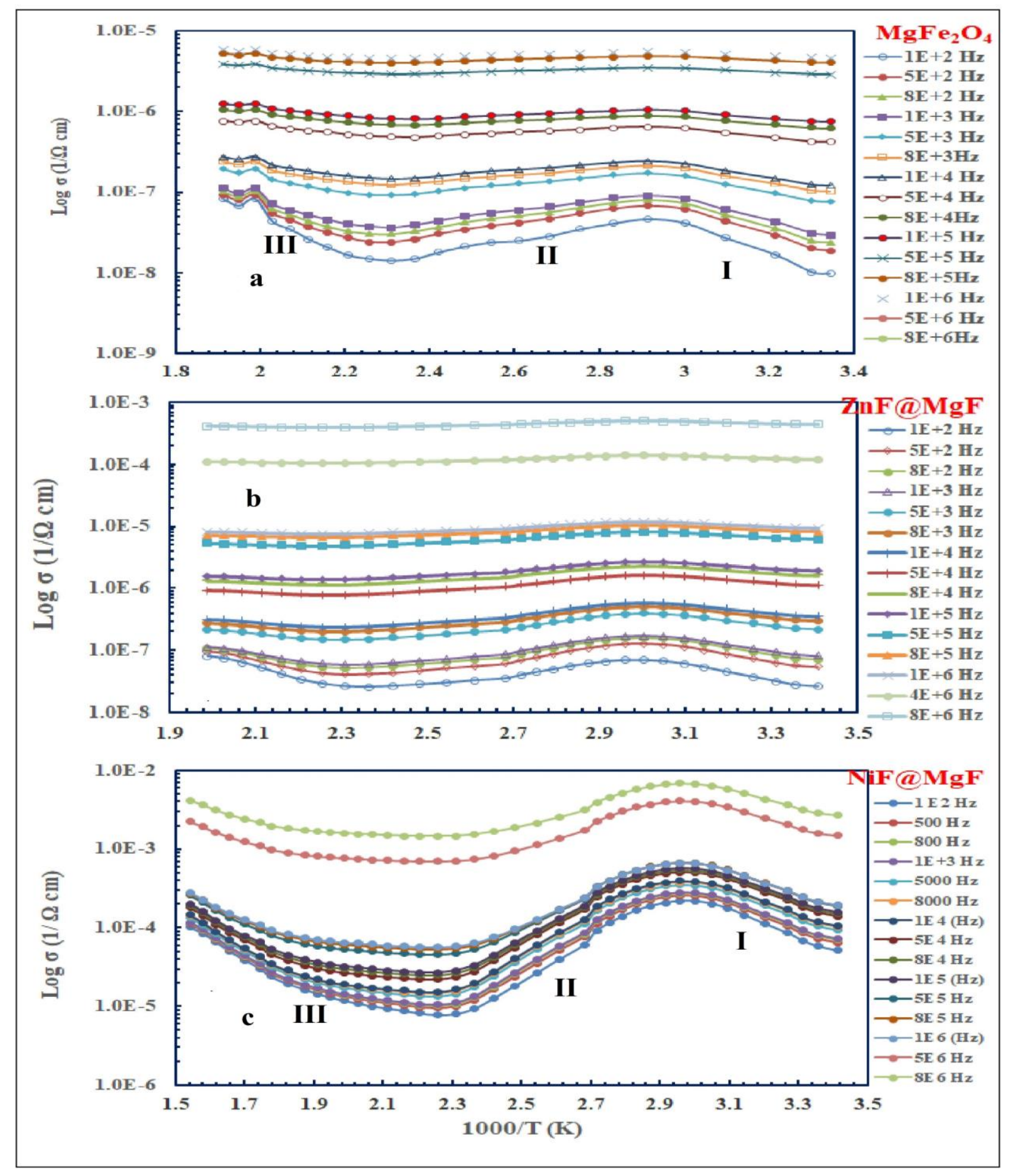

Fig 7. 


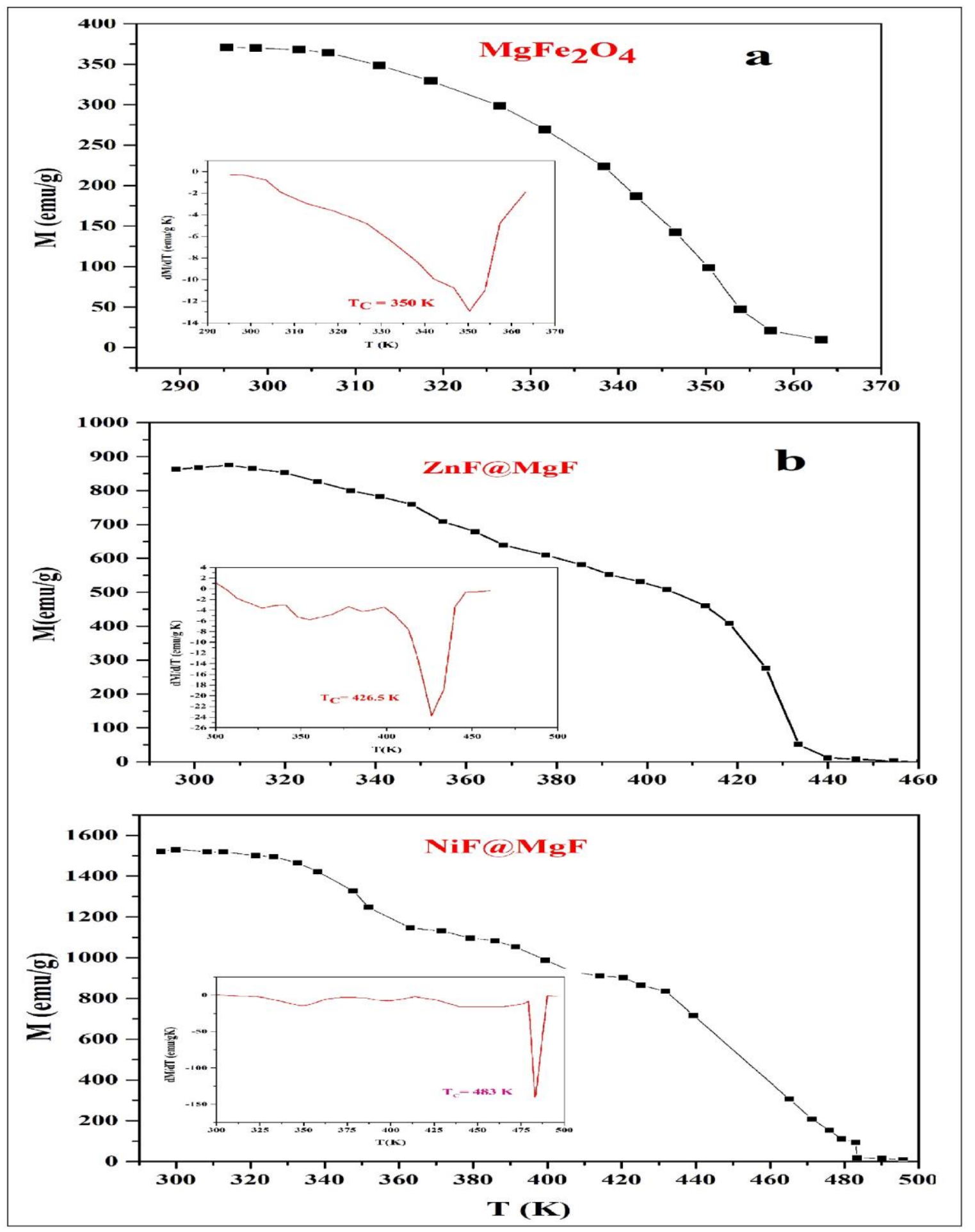

Fig 8 . 


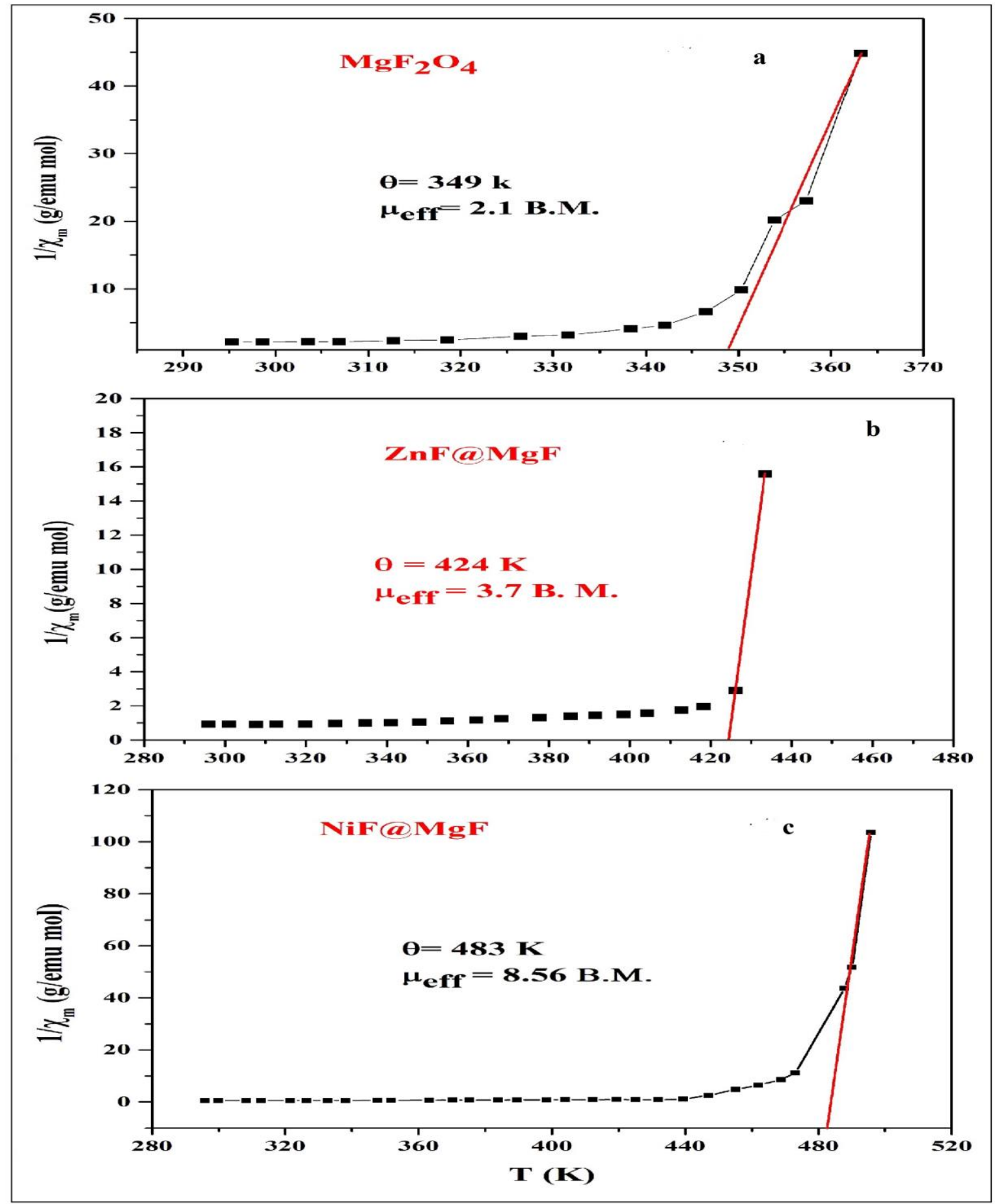

Fig 9. 
Figures

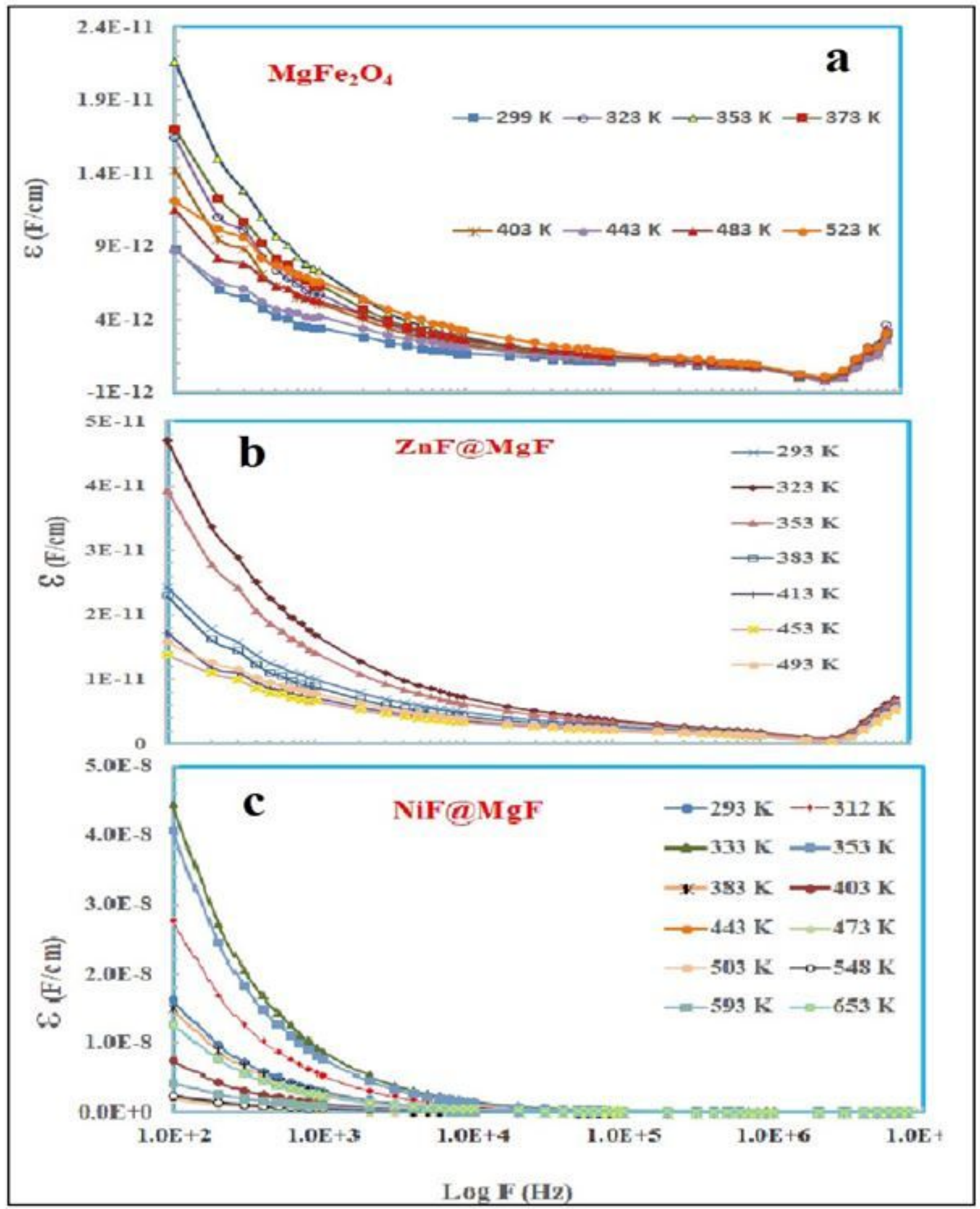

\section{Figure 1}

Frequency dependence of $\otimes$ at different temperatures for a) MgF, b) ZnF@MgF and c) NiF@MgF. 


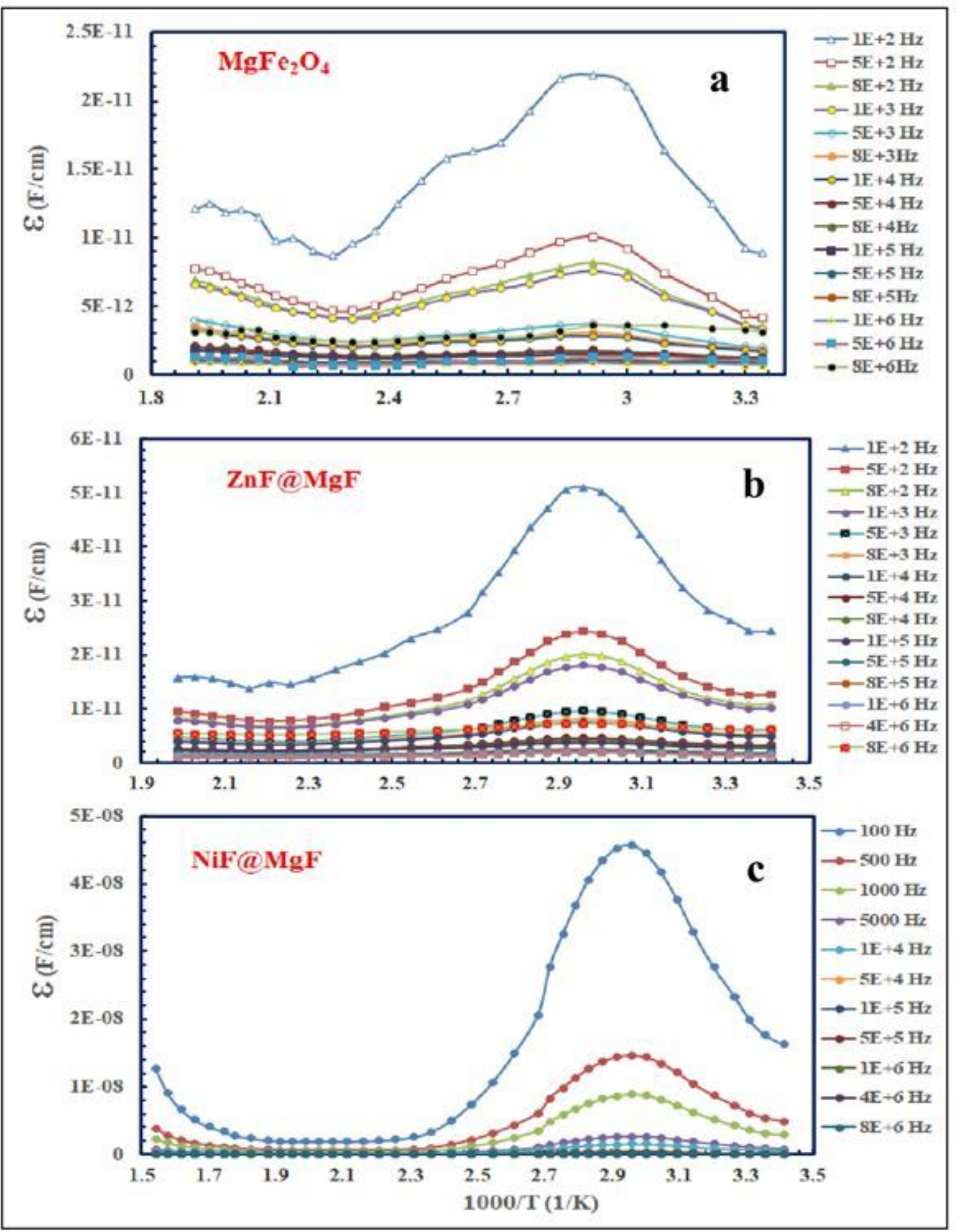

Figure 2

Temperature dependence of $₫$ at different frequencies for a) MgF, b) ZnF@MgF and c) NiF@MgF. 


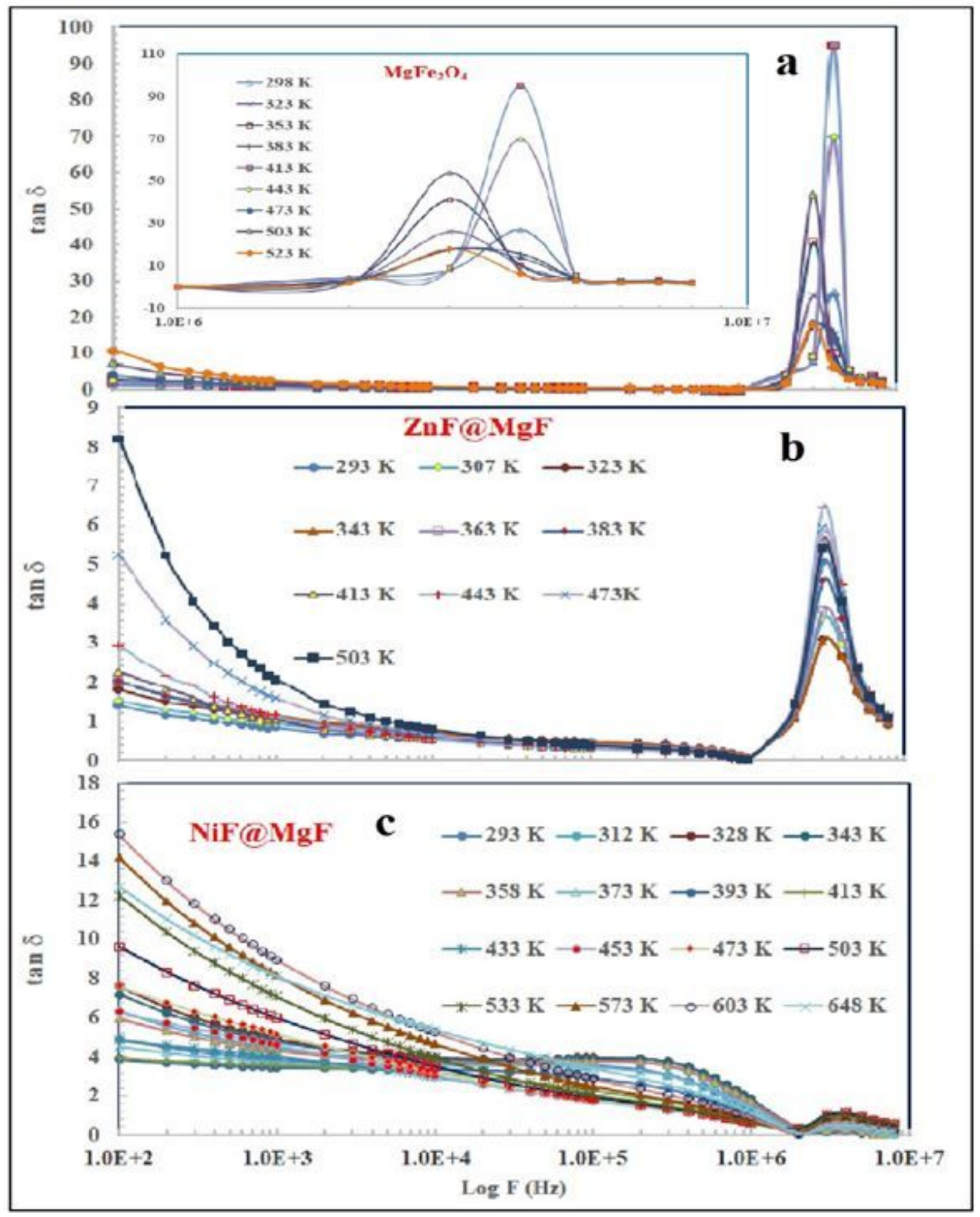

Figure 3

Frequency dependence of $\tan 囚$ at different temperatures for a) MgF, b) ZnF@MgF and c) NiF@MgF. 


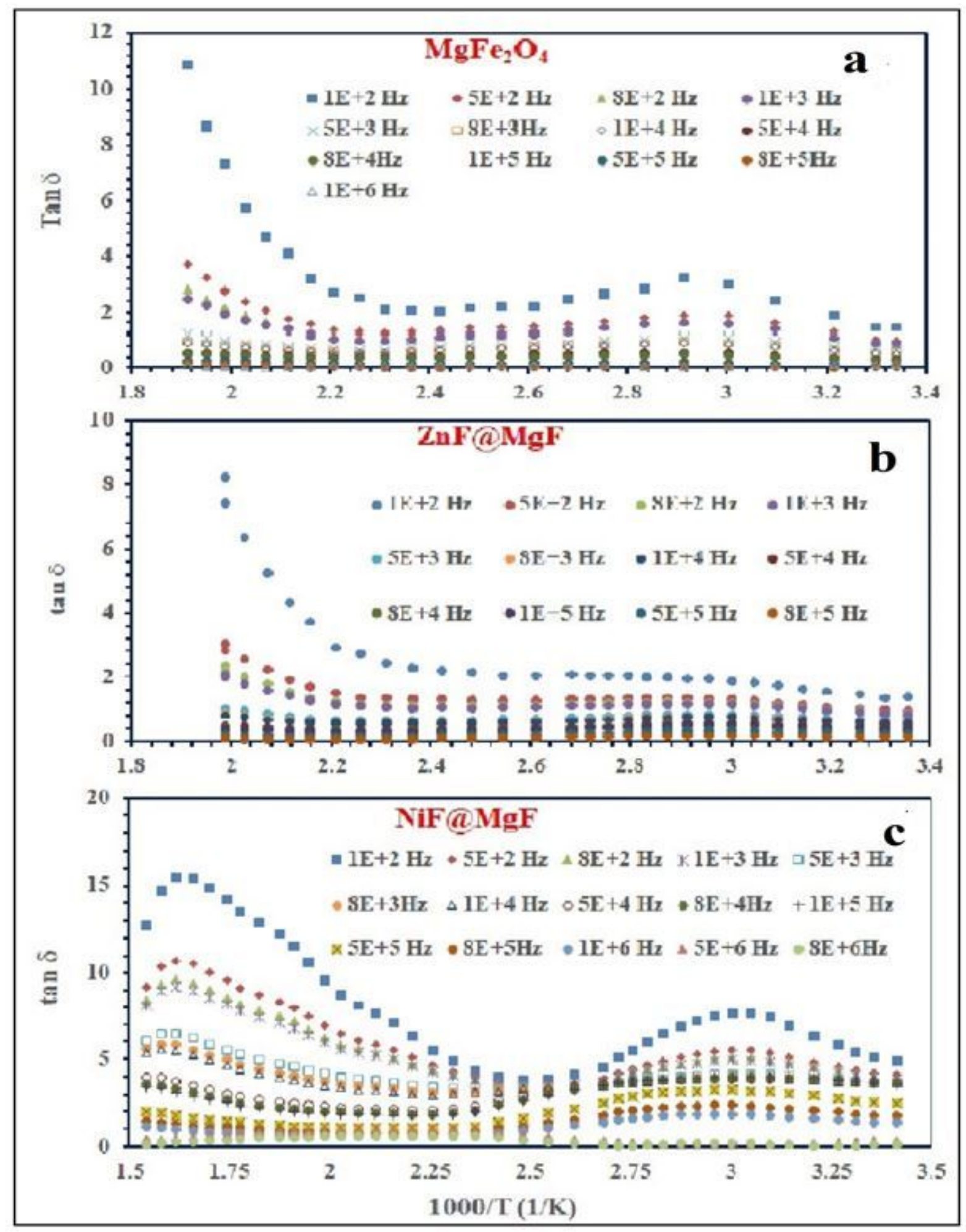

Figure 4

Temperature dependence of $\tan \varangle$ at different frequencies for a) MgF, b) ZnF@MgF and c) NiF@MgF. 


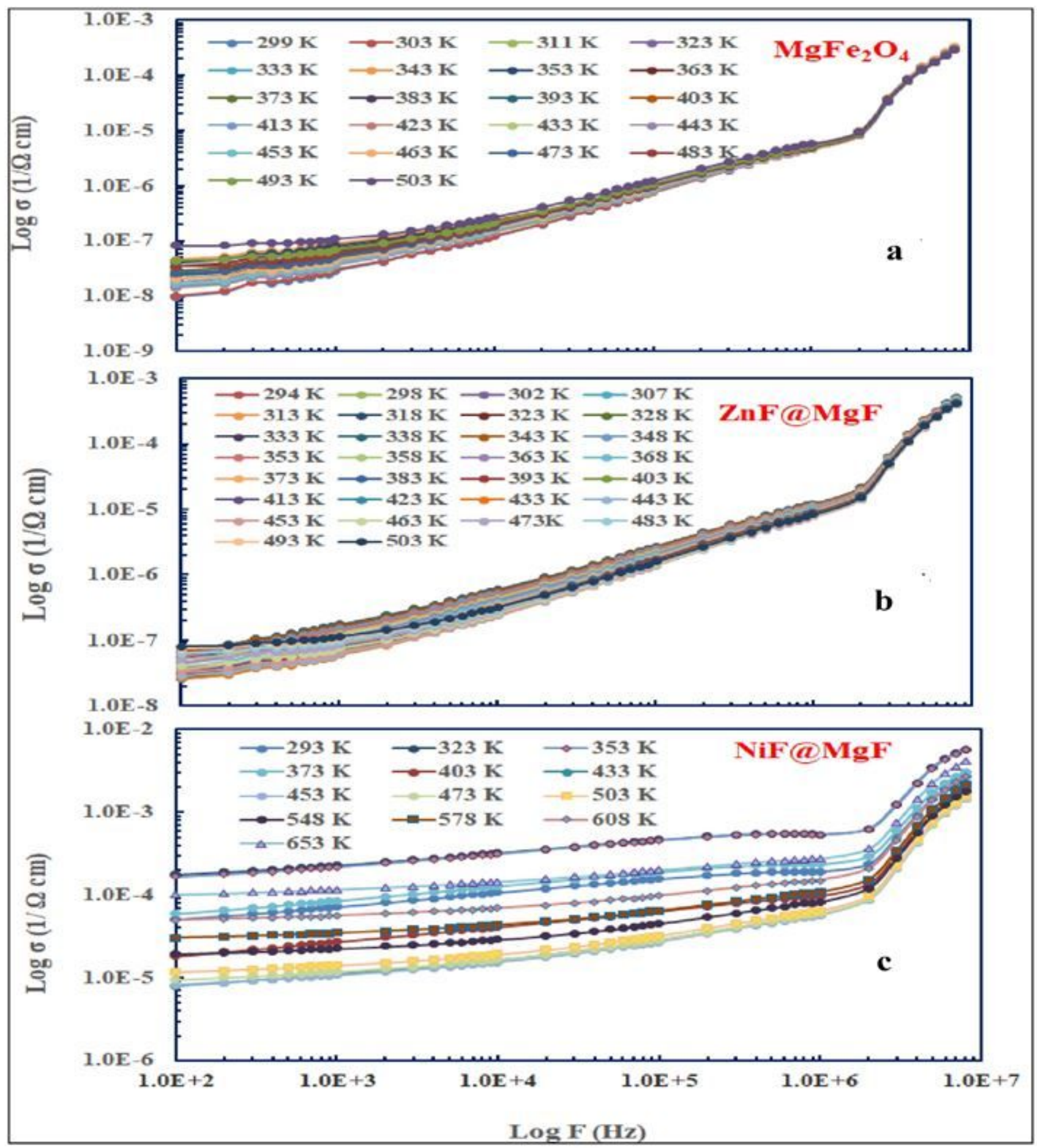

Figure 5

Frequency dependence of $\log (\sigma)$ at different temperatures for a) MgF, b) ZnF@MgF and c) NiF@MgF. 


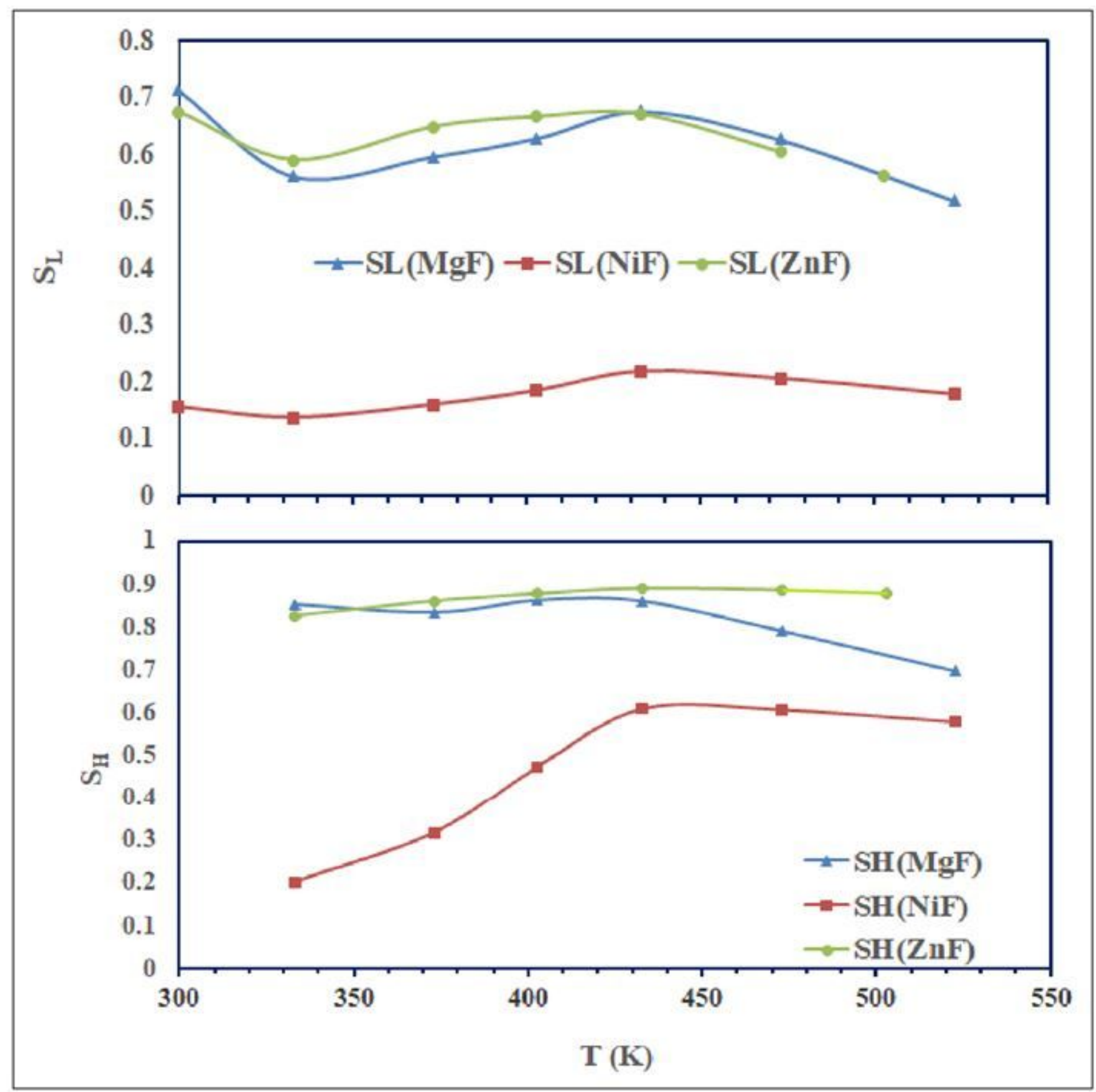

Figure 6

the exponent (s) versus $\mathrm{T}(\mathrm{K})$. 


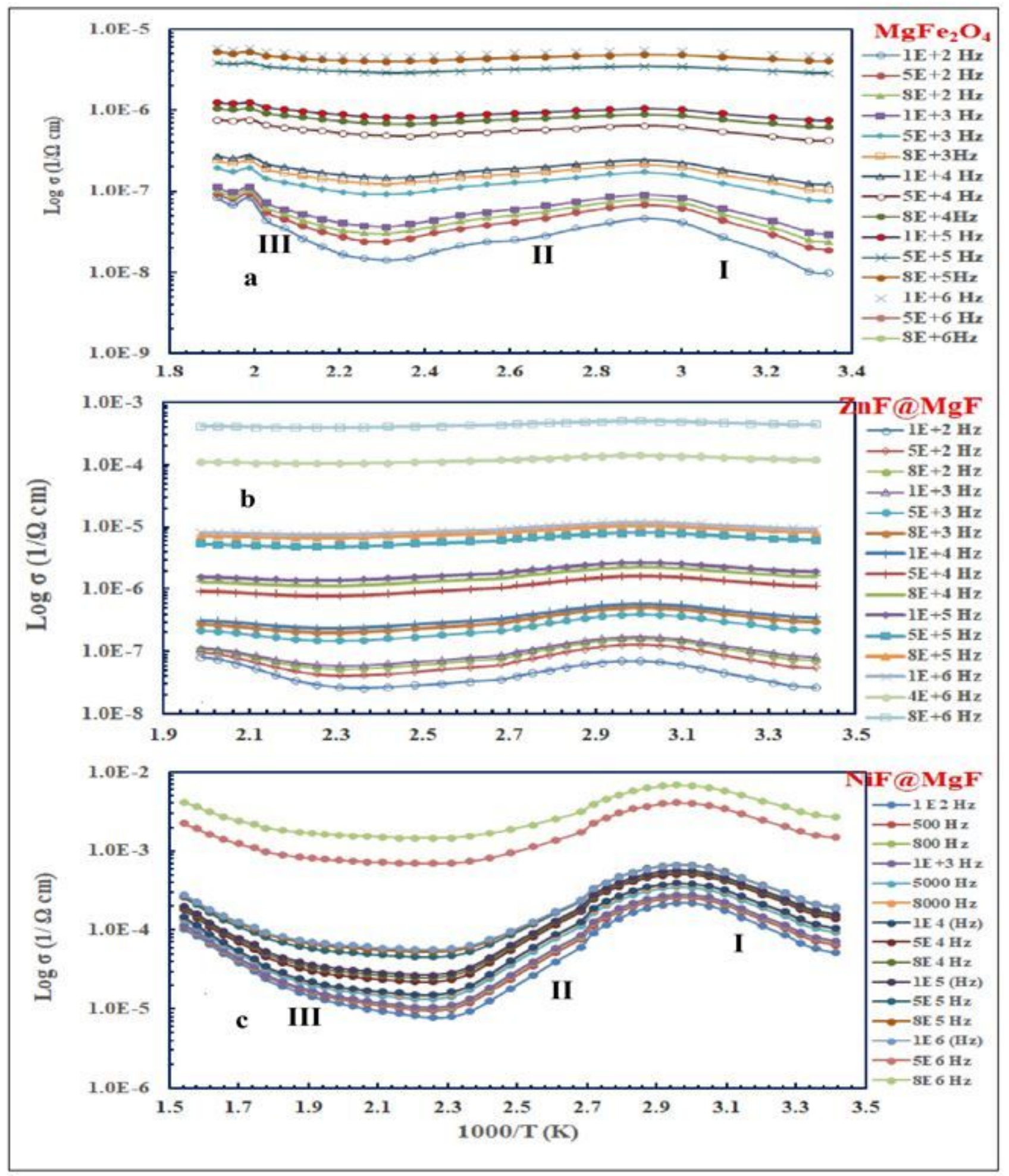

Figure 7

The Conductivity $\log (\sigma)$ versus 1000/T for a) MgF, b) ZnF@MgF and c) NiF@MgF. 


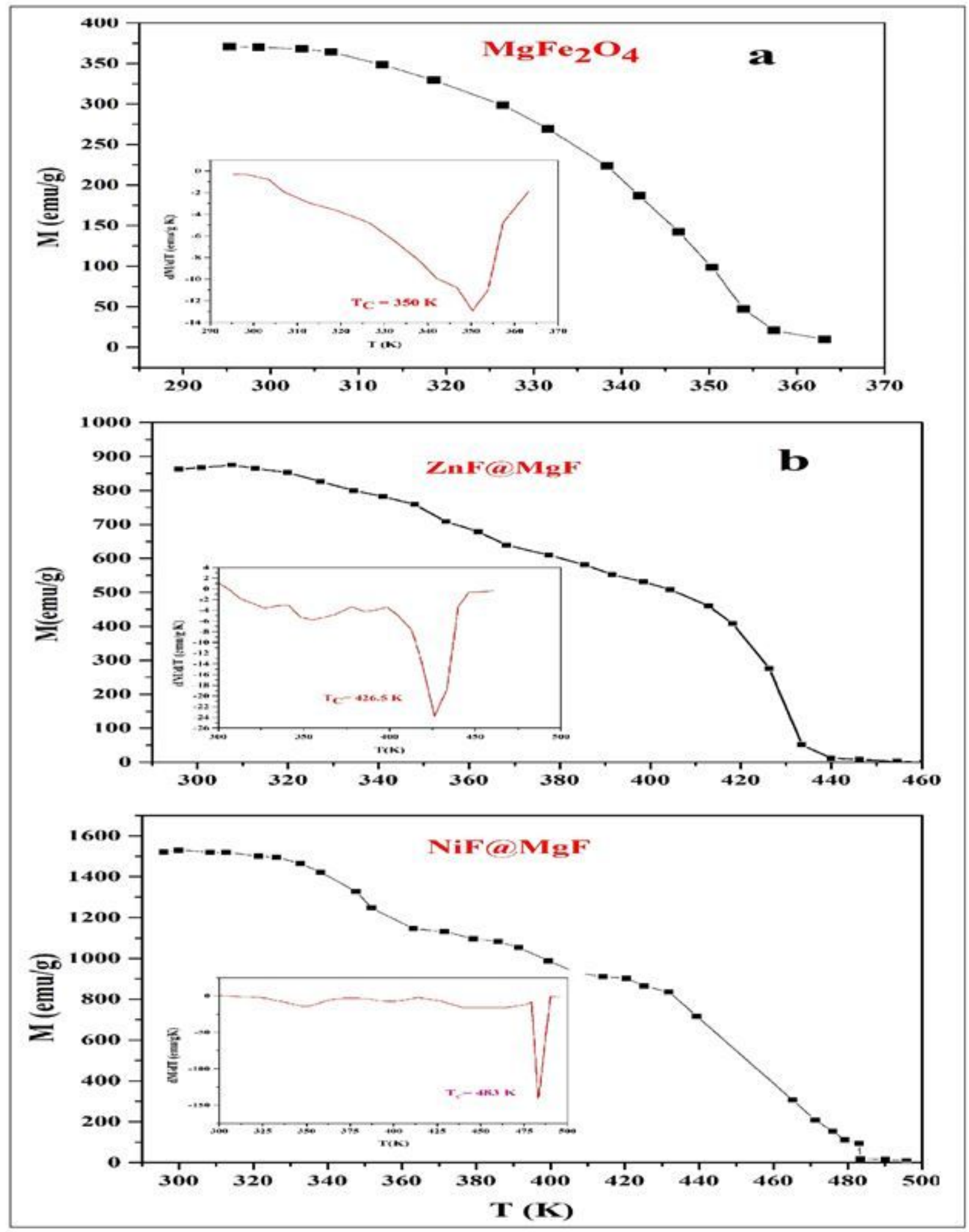

Figure 8

Temperature dependence of the magnetization for a) MgF, b) ZnF@MgF and c) NiF@MgF. 


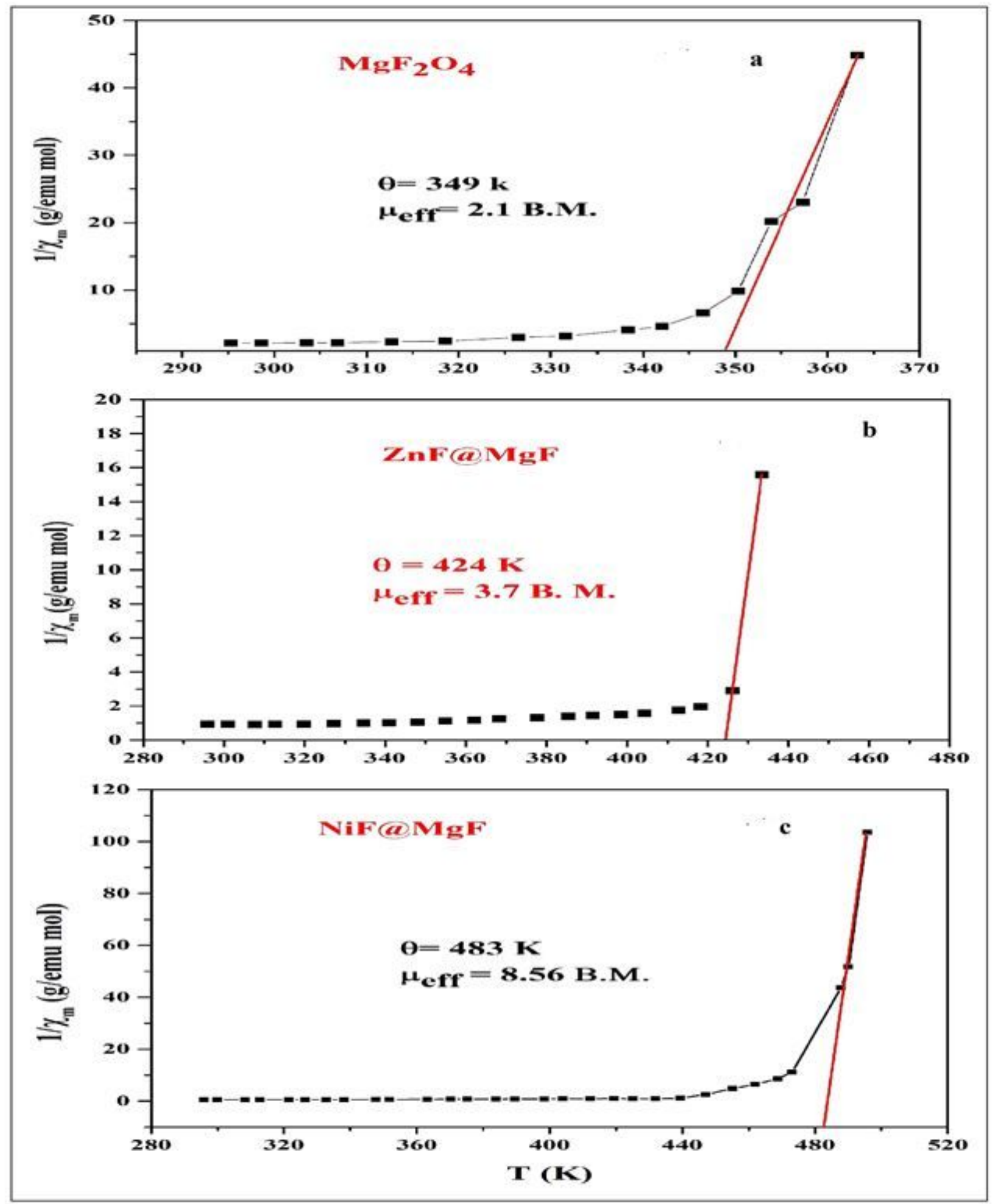

Figure 9

Temperature dependence of the xm-1 for a) MgF, b) ZnF@MgF and c) NiF@MgF. 